\title{
Immunological mechanisms of human resistance to persistent Mycobacterium tuberculosis infection
}

\author{
Jason D. Simmons ${ }^{1}$, Catherine M. Stein ${ }^{2,3}$, Chetan Seshadri ${ }^{1}$, Monica Campo ${ }^{1}$, \\ Galit Alter , Sarah Fortune, Erwin Schurr ${ }^{6}$, Robert S. Wallis ${ }^{3,7}$, Gavin Churchyard ${ }^{7}$, \\ Harriet Mayanja-Kizza ${ }^{8}{ }^{8}$, W. Henry Boom ${ }^{3}$ and Thomas R. Hawn ${ }^{1}$
}

Abstract | Mycobacterium tuberculosis is a leading cause of mortality worldwide and establishes a long-lived latent infection in a substantial proportion of the human population. Multiple lines of evidence suggest that some individuals are resistant to latent $M$. tuberculosis infection despite long-term and intense exposure, and we term these individuals 'resisters'. In this Review, we discuss the epidemiological and genetic data that support the existence of resisters and propose criteria to optimally define and characterize the resister phenotype. We review recent insights into the immune mechanisms of $M$. tuberculosis clearance, including responses mediated by macrophages, T cells and B cells. Understanding the cellular mechanisms that underlie resistance to $M$. tuberculosis infection may reveal immune correlates of protection that could be utilized for improved diagnostics, vaccine development and novel host-directed therapeutic strategies.

Purified protein derivative (PPD) skin reactivity test

A delayed-type

hypersensitivity test that

measures induration at the site of an intradermal injection of peptide extract from mycobacterial culture filtrate A positive result reflects a prespecified minimal diameter of skin induration and suggests the presence of latent Mycobacterium tuberculosis infection but may also result from non-M. tuberculosis sensitization, including prior vaccination with

Mycobacterium bovis Bacillus Calmette-Guérin. Also known as the Mantoux tuberculin skin test (TST)

Bacillus Calmette-Guérin (BCG). A culture-adapted, attenuated Mycobacterium bovis strain that is used for vaccination against Mycobacterium tuberculosis. *e-mail: jasonds@uw.edu https://doi.org/10.1038/ s41577-018-0025-3
Through a long coevolutionary history with humans, Mycobacterium tuberculosis has developed into a highly successful pathogen that infects $23-32 \%$ of the world population $^{1,2}$ and tuberculosis (TB) is the leading infectious cause of death ${ }^{3}$. Following aerosol exposure to M. tuberculosis, three potential clinical outcomes are possible, namely, resistance or early clearance of the bacillus, asymptomatic or latent $M$. tuberculosis infection (LTBI) that can persist for decades, or symptomatic 'active tuberculosis', which includes pulmonary disease that can result in further transmission. Recent whole-blood transcriptomic profiling ${ }^{4,5}$ and advanced lung imaging modalities ${ }^{6}$ have provided new insight into the transition from subclinical to active $\mathrm{TB}^{7,8}$. However, why some heavily exposed individuals never acquire, or perhaps immediately eliminate, infection is poorly understood.

No reliable test exists that directly detects the presence or absence of $M$. tuberculosis in asymptomatic individuals. The purified protein derivative (PPD) skin reactivity test measures delayed-type hypersensitivity to mycobacterial antigens and has been the gold standard for the diagnosis of LTBI for $>100$ years ${ }^{9,10}$. As PPD is enriched for protein antigen ${ }^{11}$ that are not necessarily specific to M. tuberculosis, prior immunization with Mycobacterium bovis Bacillus Calmette-Guérin (BCG) or exposure to non-tuberculous mycobacteria can yield false positive results. IFN $\gamma$ release assays (IGRAs) were developed as a whole-blood diagnostic test that measures IFN $\gamma$ release from M. tuberculosis-antigen-specific $\mathrm{CD}^{+} \mathrm{T}$ cells after stimulation with two to three specific $M$. tuberculosis antigens and thus avoids false positive results from prior BCG vaccination ${ }^{8}$. In the absence of a direct measure of infection, the best surrogates for initial infection are the PPD skin reactivity test and/or IGRA responses that convert from negative to positive (that is, incident positive) after $M$. tuberculosis exposure.

In endemic TB settings, some adults who are heavily and repeatedly exposed to $M$. tuberculosis remain negative for reactivity in the PPD test and the IGRA. These individuals, whom we term resisters, can be defined clinically as resistant to infection (FIG. 1). However, as this designation includes several assumptions about exposure and the stability of the results of these diagnostic tests, we propose the following enrolment criteria for studies of resisters (BOX 1). First, a high level of exposure is crucial and should include indices of exposure intensity (for example, high bacillary load of a known index case and close proximity of contact, such as sharing a room or bed) as well as indices of exposure duration that capture cumulative exposure (for example, repeated household exposures or employment in settings of documented high $M$. tuberculosis transmission), all of which can be assessed using validated exposure risk scores ${ }^{12,13}$. Second, diagnosis of a resister requires a negative result for both the PPD skin reactivity test and the IGRA to avoid misclassification. Third, these diagnostic tests should be carried out serially following documented exposures to capture any conversions to LTBI (or TB). 


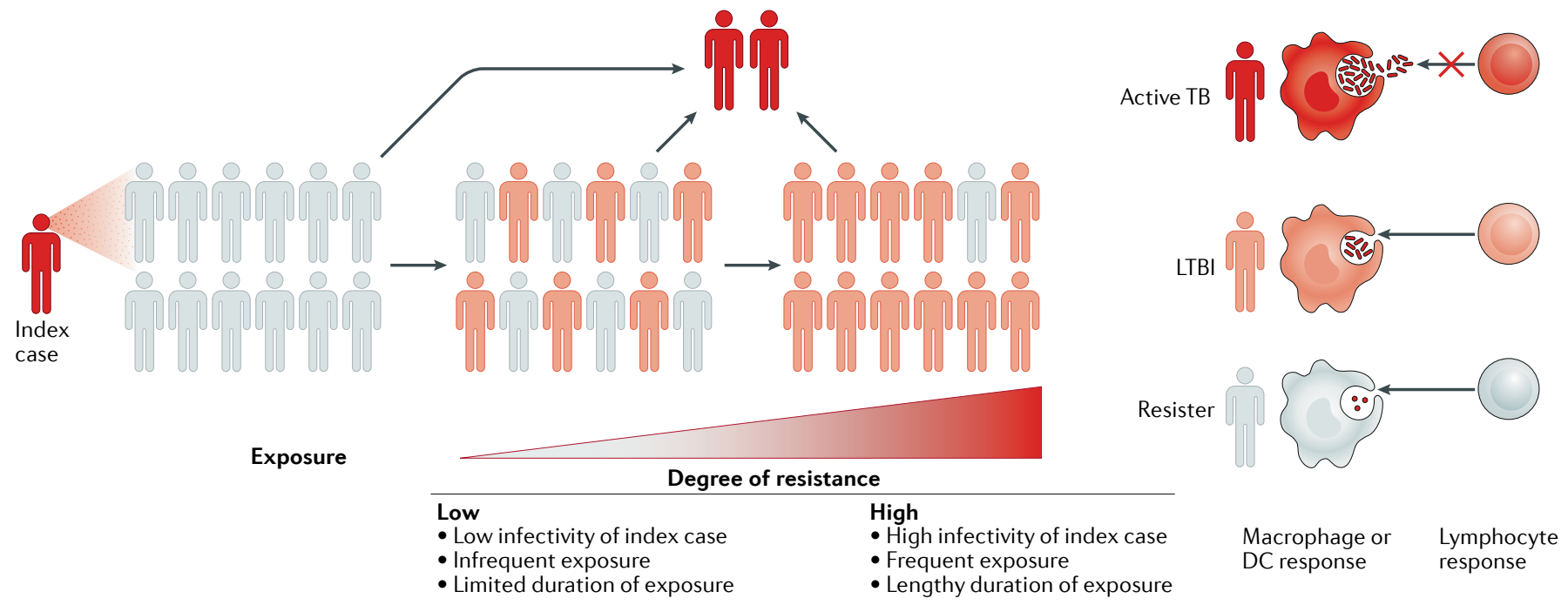

Fig. 1 | The spectrum of human resistance to infection by Mycobacterium tuberculosis. The extent of resistance to Mycobacterium tuberculosis infection is proportional to the duration and the intensity of exposure to M. tuberculosis. Individuals who resist infection despite heavy exposure to $M$. tuberculosis are more likely to have immunogenetic mechanisms of resistance than those who resist infection after a lower extent of exposure. Individuals with resistance to M. tuberculosis infection after intense exposure are termed 'resisters' (white), whereas individuals who test positive in the purified protein derivative (PPD) skin reactivity test and/or the IFN $\gamma$ release assay (IGRA) can either be asymptomatic (latent M. tuberculosis infection (LTBI); pink) or be symptomatic with tuberculosis (TB; red). DC, dendritic cell.

IFN $\gamma$ release assays (ICRAs). Whole-blood immune assays in which a patient's blood is cultured in the presence of select antigens specific to Mycobacterium tuberculosis and the secretion of IFN $\gamma$ is quantified. Positive results are independent of prior Bacillus Calmette-Guérin vaccination and negative results ensure a sufficient response to

Resister

An individual who remains negative for the purified protein derivative skin reactivity test and the IFN $\gamma$ release assay throughout serial testing despite heavy exposure to Mycobacterium tuberculosis a mitogen positive control.

The resister phenotype is probably heterogeneous and might involve innate immunological mechanisms of early clearance of $M$. tuberculosis (innate resisters). Alternatively, protective immunity might also occur through adaptive immune responses (adaptive resisters), including IFN $\gamma$-independent responses that have been measured in preclinical models ${ }^{14-16}$, and thus a potential role for B cell or unconventional $\mathrm{T}$ cell responses in early clearance of $M$. tuberculosis should be considered. Longitudinal, rigorous epidemiological studies of resisters, together with data from genetic and immunological platforms, are providing new insights into human resistance to $M$. tuberculosis infection.

In this Review, we describe the epidemiology of the resister phenotype and discuss several caveats about the definition of a resister. Next, we review the genetic determinants of the resister phenotype and discuss potential effector mechanisms in macrophages, unconventional $\mathrm{T}$ cells and B cells. We examine immune factors that prevent or limit $M$. tuberculosis infection in innate resisters or adaptive resisters, which could be harnessed for the

\section{Author addresses}

'Department of Medicine, University of Washington, Seattle, WA, USA.

${ }^{2}$ Department of Population \& Quantitative Health Sciences, Case Western Reserve University, Cleveland, $\mathrm{OH}, \mathrm{USA}$.

${ }^{3}$ Department of Medicine, Case Western Reserve University, Cleveland, OH, USA.

${ }^{4}$ Ragon Institute of MGH, MIT and Harvard, Cambridge, MA, USA.

${ }^{5}$ Department of Immunology and Infectious Diseases, Harvard School of Public Health, Boston, MA, USA.

${ }^{6}$ Program in Infectious Diseases and Immunity in Global Health, Research Institute of the McGill University Health Centre, Montreal, Québec, Canada.

${ }^{7}$ The Aurum Institute, Parktown, South Africa.

${ }^{8}$ Department of Medicine, School of Medicine, Makerere University, Kampala, Uganda.
}

development of host-directed therapies or more effective vaccines and adjuvants.

\section{Epidemiology}

Despite the absence of a direct microbiological measure of M. tuberculosis in latent infection, historical and rigorous modern epidemiological studies suggest that resisters exist, although their estimated frequency varies in different studies.

Historical case-contact studies. Strong epidemiological evidence suggests that some individuals are naturally resistant to infection, even after heavy exposure to M. tuberculosis in closed environments. In 1966, all enlisted personnel and officers aboard the destroyer U.S.S. Richard E. Byrd were enrolled in a study after a $5 \mathrm{~cm}$ pulmonary cavity was detected (by radiography) in a crew member who suffered progressive respiratory symptoms for the prior 6 months aboard the ship ${ }^{17}$. Of the 308 at-risk enlisted crew members, 7 developed active TB, 6 of whom shared the same berthing compartment as the index case. Most crew members in this 'high-burden' compartment showed evidence of new infection (either active TB or an incident positive PPD), whereas seven crew members $(\sim 10 \%)$ were negative for the PPD skin test during the initial study and remained so at follow-up. Other studies, including an evaluation of nursing students in the pre-antibiotic era, also showed evidence of PPD-negative responses despite intense exposure to patients with TB (TABLE 1). A systematic review of household contact studies detected heterogeneity in resistance to infection, with an average of $50 \%$ of close contacts remaining uninfected ${ }^{18}$. However, these studies reveal substantial variability in PPD-conversion rates, which is consistent with unmeasured exposure variables. 
Innate resisters

Conceptually, resisters

who immediately clear

Mycobacterium tuberculosis

following exposure to the

bacterium and before priming

of any adaptive immune

responses.

Adaptive resisters

Conceptually, resisters who

Mycobacterium tuberculosis infection via T cell and B cell mechanisms but who remain negative for the purified protein derivative skin reactivity test and the IFN $\gamma$ release assay.

Household contact An individual who resides within the same domicile as an index case (patient with tuberculosis) for a pre-specified amount of time.

Hyperendemic conditions Regions in which ongoing Mycobacterium tuberculosis transmission is unusually high owing to an elevated prevalence of tuberculosis.

Silicosis

An occupational pulmonary disease that is prevalent among gold miners owing to protracted inhalation of silicate dust, which leads to scarring and increased Mycobacterium tuberculosis infection. clear or contain

Not surprisingly, proximity and duration of contact with the index case as well as the infectivity of the index case (that is, bacillary burden) were predictors of PPD conversion.

The results of most early studies in hyperendemic conditions suggest that a minority of the population (5-50\%) has the resister phenotype, and this variability probably reflects exposure intensity and the duration of follow-up ${ }^{17,19,20}$. However, the results of some studies suggest that rates of resistance are higher (for example, up to $70 \%$ of exposed individuals are resisters), even after periods of high exposure (that is, sleeping in the same bed or room) to the index case ${ }^{21-24}$. Importantly, most of these studies either had a short duration of follow-up or contained data that were difficult to accurately review by modern epidemiological standards. Finally, the strain of $M$. tuberculosis probably differed among the various studies and thus might affect transmission rates. For example, increased virulence and transmission might be one of several factors that are involved in the increased range and incidence of the lineage 2 /Beijing strains of M. tuberculosis ${ }^{25-27}$.

The results of these early studies suggest that a resister phenotype exists, but the epidemiological methods that were used could not ensure high exposure and adequate follow-up to confirm the presence of clinical resistance to $M$. tuberculosis infection.

Contemporary cohort studies. Population studies of individuals in hyperendemic TB settings in the past 5 years have provided opportunities to examine resistance to $M$. tuberculosis infection. For example, among South African gold miners, exposure to silica dust and the congregate working, living and social conditions that are associated with mining contribute to the high level of ongoing M. tuberculosis transmission ${ }^{28,29}$. Mathematical modelling suggests that the annual risk of infection (that is, conversion in the PPD skin test) among gold miners is as high as $20 \%^{30}$. The prevalence of LTBI in these gold miners was estimated at $89 \%$, and $13 \%(15 / 115)$ of HIV-negative participants showed no evidence of

\section{Box 1 | Proposed criteria to define the resister phenotype}

Resisters (individuals who show resistance to Mycobacterium tuberculosis infection despite long-term, intense exposure to the bacillus) are exemplified by the following characteristics:

\section{Extent of exposure to Mycobacterium tuberculosis}

- Intensity: high bacillary burden of index case (for example, sputum-positive), closed environment (household, mine shafts and so on) and use of validated epidemiological risk scoring ${ }^{12,13}$

- Duration: cumulative exposures (that is, health-care workers, miners, household contacts or adults with community exposure in hyperendemic areas)

\section{Result of diagnostic tests}

- Negative result in both the purified protein derivative (PPD) skin reactivity test and the IFN $\gamma$ release assay (IGRA)

\section{Durability of responses}

- Multiple negative results for the PPD skin reactivity test and the IGRA in the first year following exposure

- Additional longitudinal testing, when available and if exposures persist, to minimize false negative test results and enrich for conversions after cumulative exposure
M. tuberculosis infection (that is, induration $=0 \mathrm{~mm}$ in the PPD skin test) ${ }^{31}$. In this extremely high-burden environment, any gold miners who remain persistently uninfected are likely resisters. According to mathematical models, the likelihood that a 40 -year-old gold miner without evidence of $M$. tuberculosis infection (induration $=0 \mathrm{~mm}$ in the PPD skin test) is a resister is $93 \%$, compared with only $22 \%$ among the general community ${ }^{32}$. Two prospective studies in South Africa are currently being carried out to identify HIV-uninfected or HIV-infected resisters who have been mining for $\geq 15$ years, are 33-60 years of age, do not have evidence of past or active TB or silicosis and have neither a history of treatment for LTBI nor any non-HIV immunosuppressive conditions.

Few longitudinal studies of conversion in the PPD skin reactivity test or the IGRA in hyperendemic settings have incorporated extended follow-up periods. Uganda is a high-burden TB setting with a 3\% annual risk of $M$. tuberculosis infection, as determined by PPD skin test and/or IGRA conversion ${ }^{33}$. LTBI is considerably more prevalent among household contacts than among community members, and consequently, there is a risk difference of $30 \%$ among adults ${ }^{34}$. In Kampala, Uganda, household contacts of index cases with cultureconfirmed TB were evaluated for active TB and underwent PPD skin testing ${ }^{35}$. The annual incidence of new cases of culture-positive TB in this study was 740 per 100,000 individuals, compared with country-wide estimates of 159 per 100,000 individuals $^{33}$. If an individual was negative in the PPD skin reactivity test at baseline ( $<10 \mathrm{~mm}$ induration for HIV-negative individuals $>5$ years old, $<5 \mathrm{~mm}$ induration for HIV-negative individuals $\leq 5$ years old or $<5 \mathrm{~mm}$ induration for all HIV-positive individuals), repeated PPD skin tests were carried out at 3, 6, 12 and 24 months after enrolment. Among the entire study cohort, $11.7 \%$ of adult close household contacts remained persistently negative in the PPD skin test throughout the two year follow-up ${ }^{12,36}$. Both the South African and Ugandan cohorts described here provide an opportunity to rigorously define the resister phenotype and explore its underlying cellular mechanisms.

Complexities of the resister phenotype. Given that the definition of a resister relies on epidemiological data and utilizes an indirect, immunological measurement of M. tuberculosis infection, it is likely that some resisters are misclassified. Several alternative hypotheses may explain the resister phenotype.

Despite meeting enrolment criteria as a household contact, an individual with a negative result in the PPD skin reactivity test may simply have had insufficient exposure, either from a low intensity of exposure (that is, a low bacillary burden in the index case, minimal contact with the index case or good ventilation within the household) or a short duration of contact with an index case. In the Ugandan study, a published modified epidemiological exposure risk score ${ }^{13}$, consisting of characteristics of the TB index case and the intensity of the contact with the index case, did not differ between resisters and individuals with LTBI $^{12}$. This result suggested that all household contacts were highly exposed to M. tuberculosis. Participants in the Ugandan household 
Table 1 Prevalence of the resister phenotype

\begin{tabular}{|c|c|c|c|}
\hline Exposed population & Length of follow-up & $\begin{array}{l}\text { Cumulative } \\
\text { resister prevalence } \\
\text { (percentage) }^{\mathrm{a}}\end{array}$ & Refs \\
\hline \multicolumn{4}{|c|}{ Historical purified protein derivative studies } \\
\hline $\begin{array}{l}\text { Sailors sharing berthing } \\
\text { compartment with an } \\
\text { individual with active TB }\end{array}$ & $>6$ months & $9 / 65(13.8)$ & 17 \\
\hline $\begin{array}{l}\text { Sailors with frequent } \\
\text { contact with two individuals } \\
\text { with incident TB aboard ship }\end{array}$ & $6-12$ months & $76 / 226(33.7)$ & 173 \\
\hline $\begin{array}{l}\text { Young nursing students } \\
\text { working in heavy-burden TB } \\
\text { hospital in Norway }\end{array}$ & 3 years & $0 / 1,453$ & 44 \\
\hline $\begin{array}{l}\text { Nursing students at } \\
\text { Philadelphia General } \\
\text { Hospital (USA) in 1935-1939 }\end{array}$ & 3 years & $0 / 637$ & 45 \\
\hline $\begin{array}{l}\text { Nurses training at Boston } \\
\text { City Hospital (USA) in } \\
\text { 1932-1936 }\end{array}$ & 3 years & $6 / 126(4.8)$ & 174 \\
\hline $\begin{array}{l}\text { University of Minnesota } \\
\text { nursing classes graduating } \\
\text { in 1932-1935 (before } \\
\text { removal of TB ward and } \\
\text { installation of infection } \\
\text { control) }\end{array}$ & 3 years & $16 / 184(8.7)$ & 175 \\
\hline \multirow{2}{*}{$\begin{array}{l}\text { Professional students of } \\
\text { Wisconsin General Hospital } \\
\text { and Wisconsin State } \\
\text { Sanatorium in 1934-1944 } \\
\text { (RNs) and 1934-1943 (MDs) }\end{array}$} & RNs: 3 years & RNs: 30/112 (26.8) & 176 \\
\hline & MDs: 4 years & MDs: 50/283 (17.7) & \\
\hline $\begin{array}{l}\text { Close family contacts of } \\
\text { index pulmonary TB cases } \\
\text { in India }\end{array}$ & $\begin{array}{l}5 \text { years following } \\
\text { diagnosis of index case }\end{array}$ & $110 / 851(12.9)$ & 22 \\
\hline $\begin{array}{l}\text { Close family contacts of } \\
\text { individuals with pulmonary } \\
\text { TB in Pakistan }\end{array}$ & $\begin{array}{l}6 \text { months following } \\
\text { diagnosis of index case }\end{array}$ & $103 / 292(35.3)$ & 21 \\
\hline $\begin{array}{l}\text { Household contacts of index } \\
\text { cases with sputum positive } \\
\text { for the AFB-smear test }\end{array}$ & $\begin{array}{l}12 \text { months following } \\
\text { diagnosis of index case }\end{array}$ & $83 / 253(32.8)$ & 23 \\
\hline \multicolumn{4}{|l|}{ Contemporary studies } \\
\hline Gold miners in South Africa & Variable & $15 / 115(13.0)$ & 31,32 \\
\hline $\begin{array}{l}\text { Close household contacts of } \\
\text { individuals with pulmonary } \\
\text { TB in Uganda }\end{array}$ & 2 years & $142 / 1,210(11.7)$ & 12,177 \\
\hline \multicolumn{4}{|c|}{$\begin{array}{l}\text { AFB, acid fast bacilli; MDs, medical students; RNs, nursing students; TB, tuberculosis. } \\
\text { aThe number of contacts persistently negative for reactivity in the purified protein derivative } \\
\text { (PPD) skin test (and the IFN r release assay, if available) as a proportion of all contacts enrolled } \\
\text { in the study (that is, PPD-positive contacts, PPD-negative contacts and PPD converters). }\end{array}$} \\
\hline
\end{tabular}

contact study were re-contacted 8-10 years after the original study and were tested multiple times with IGRAs (3 assays over 3 years) and once with a repeat PPD skin reactivity test. Although they were not necessarily reexposed within the same household in the interval since their initial enrolment as a household contact, all these individuals continued to live in areas of Kampala with high TB prevalence in which community exposure to M. tuberculosis might be substantial ${ }^{37-39}$. These data will further clarify the durability of the resister phenotype.

An alternative explanation for the resister phenotype is that persistently negative results in PPD skin reactivity tests or IGRAs are false negative results owing to the inherent limitations of an immunological definition of a clinical phenotype. Both PPD skin test and IGRA responses are incomplete measures of anti-mycobacterial immunity for a number of reasons. As discussed later, these LTBI diagnostic tests fail to detect the response of $\mathrm{T}$ cells that are specific for nonprotein mycobacterial antigens via $\mathrm{MHC}$-independent pathways, and IGRAs do not detect the response of antigen-specific $\mathrm{T}$ cells with alternative (that is, IFN $\gamma$ independent) cytokine-producing profiles ${ }^{40-42}$. T cell anergy could also cause false negative results in the PPD skin test. In the Uganda study, HIV-negative individuals were not more likely to be PPD-negative than HIV-positive individuals, for whom a positive PPD test was defined as induration $>5 \mathrm{~mm}\left(\mathrm{REF}^{12}\right)^{12}$. Furthermore, in recent follow-up studies, all resisters demonstrated reactivity to the mitogen positive control that was included in the IGRA methodology (W.H.B. and C.M.S., unpublished observation), suggesting that generalized $\mathrm{CD}^{+}$ $\mathrm{T}$ cell anergy or depletion alone does not explain the resister phenotype. This does not rule out a contribution of pathogen-specific anergy, which has been observed in human lepromatous leprosy ${ }^{43}$.

Resistance to $M$. tuberculosis probably has a threshold, above which relative resistance can be overcome by a sufficiently high exposure. For example, in two landmark studies in the 1930s and 1940s in Norway and at the Philadelphia General Hospital, USA, the prevalence of LTBI among nursing students at matriculation was $45.3 \%$ $(668 / 1,453)^{44}$ and $57 \%(366 / 643)^{45}$, respectively. At 3-year follow-up, however, $100 \%$ of students that were initially negative for the PPD skin test in both studies converted, and the majority of these negative-to-positive conversions occurred during the early stages of training. Considering these data, together with those from the contemporary studies discussed earlier, it is possible that repeated testing (for example, serial testing every 4 months with 2 doses $^{45}$ ) and the use of tuberculin of non-standardized purity (for example, the two early studies were carried out before large-scale standardized preparations of tuberculin, such as PPD-S, became available in 1941) effectively sensitized some individuals in the absence of natural infection. Non-tuberculous mycobacterial infections are also known to produce false positive results in the PPD skin test in some populations, a response that could potentially be boosted by serial PPD testing, as was seen with $M$. tuberculosis infection ${ }^{46}$. Furthermore, the induration thresholds that were used for each method (Mantoux or von Pirquet) were not described in these studies. Nonetheless, the results of these pre-antibiotic era studies suggest that absolute $M$. tuberculosis resistance occurred at a low frequency in these populations.

Relative resistance to $M$. tuberculosis disease might also be a function of the infectious dose. The classical work of Lange and Chaussé showed that small droplets carrying one bacillus or a few bacilli are the effectors of aerosol transmission and that the vast majority of individuals with TB show only a single Ghon complex ${ }^{47,48}$. In natural infections, the frequency of exposure to M. tuberculosis is the most parsimonious surrogate for infectious dose, but how consistency of exposure is linked to innate resistance mechanisms is not known. 
The epidemiological studies discussed above suggest that some individuals are resistant to $M$. tuberculosis infection, as defined by a persistently negative result in the PPD skin test and/or the IGRA, despite sustained high-level exposures over extended periods of time. Furthermore, these individuals fail to develop active TB over an extended follow-up period. Future research to uncover the mechanisms that are involved in resistance to $M$. tuberculosis infection will require detailed assessments of exposure to the bacillus to define the resister phenotype (Box 1). The true prevalence of resisters among individuals who have been exposed to M. tuberculosis is not known, but evidence from studies that assessed exposure variables and included longitudinal sampling suggest that the prevalence is $<10 \%$.

\section{Genetics}

The cellular mechanisms that mediate $M$. tuberculosis resistance are unknown, although multiple susceptibility loci have been linked to or associated with the resister phenotype in genome-wide analyses.

Genetic basis of resistance to other pathogens. Genetic studies indicate that polymorphisms and mutations exist that are associated with resistance to some infections. For example, a 32 bp deletion in CC-chemokine receptor 5 (CCR5) in $\mathrm{CD}^{+} \mathrm{T}$ cells results in relative resistance to infection with R5-tropic HIV-1 and delays disease progression $^{49}$. Similarly, mutations in the gene encoding fucosyltransferase 2 (FUT2), which is required for the cell surface expression of histo-blood group antigens (HBGAs; the receptors for norovirus), results in decreased HBGA levels on mucosal surfaces and thus prevents virus uptake and entry into epithelial cells. Consequently, individuals with these FUT2 mutations are completely (100\% penetrant) resistant to Norwalk and other norovirus genogroups ${ }^{50,51}$. Atypical chemokine receptor 1 (ACKR1; also known as DARC and CD234) is the receptor on erythrocytes for Plasmodium vivax. Most west African individuals are homozygous for a promoter mutation that ablates ACKR1 expression in erythrocytes and, consequently, are resistant to $P$. vivax infection $^{52}$. Although these examples show Mendelian inheritance (for example, single-gene-inactivating mutations that result in highly penetrant resistance), it is likely that complex polygenic inheritance patterns are important for resistance to other pathogens, including M. tuberculosis.

Genetic studies of purified protein derivative skin reactivity. Numerous lines of evidence, including results from $\operatorname{twin}^{53,54}$, Mendelian primary immunodeficiency ${ }^{55}$, genome-wide linkage ${ }^{56-58}$ and candidate-gene studies ${ }^{59,60}$, suggest that host genetics influences susceptibility to TB. Mendelian Susceptibility to Mycobacterial Disease (MSMD) is an immunodeficiency disorder in young children who are susceptible to disseminated BCG and non-tuberculous mycobacteria and who have mutations in the IFN $\gamma$ and IL-12 signalling pathways ${ }^{55}$. Several studies also suggest that host genetic factors modulate resistance to $M$. tuberculosis infection. For example, the intensity of tuberculin reactivity after exposure to household contacts is correlated among siblings but not among unrelated children of the same household ${ }^{61}$.

In a genome-wide linkage analysis of the Ugandan cohort, suggestive evidence for a linkage of regions on chromosome 2q21-2q24 and chromosome 5p13-5q22 to the resister phenotype was detected ${ }^{57}$. These regions are distinct from the regions that are linked to protection from $\mathrm{TB}$, suggesting that the genetic underpinnings of these two ends of the TB spectrum (that is, asymptomatic infection and clinical disease) are unique. In a low endemicity setting, a candidate-gene association study of individuals with or without LTBI who had close contact with an index pulmonary TB case reported that polymorphisms in Toll-interacting protein (TOLLIP) and Unc51-like kinase 1 (ULK1) were associated with LTBI susceptibility ${ }^{62,63}$. The specific roles of these proteins in the resister phenotype are discussed later.

Another genome-wide analysis assessed PPD skin test reactivity in M. tuberculosis-exposed South African individuals. This cross-sectional study measured rates of PPD-positivity both as a binary trait (that is, $P P D=0 \mathrm{~mm}$ versus $>0 \mathrm{~mm}$ ) and as a quantitative trait by measurement of skin induration (in millimetres) ${ }^{64}$. As a binary trait, a significant linkage signal that met the stringent genome-wide linkage cut-off was found at the TST1 locus on chromosome 11p14. Strikingly, in a later study of the same families, the TST1 locus was found to be genetically indistinguishable (at a resolution of $2-14 \mathrm{Mb}$ ) from a major quantitative trait locus (QTL) that controls tumour necrosis factor (TNF) production following stimulation of whole blood with either BCG alone or BCG plus IFN $\gamma^{65}$. These findings indicate that a genetic determinant linked to TNF secretion in response to BCG and IFN $\gamma$ might also determine PPD negativity, perhaps through TNF-induced microbicidal pathways. However, the genomic resolution around the TST1 locus in these studies was low (2-14 Mb), and this locus includes other genes besides TNF. When reactivity in the PPD skin test was measured in the same study as a quantitative trait (that is, the size of skin induration in millimetres), significant linkage was found with a second locus, TST2, on chromosome 5p15 (REF. ${ }^{64}$ ). This region of chromosome 5 overlaps with the region that was associated with the resister phenotype in the Ugandan cohort ${ }^{57}$. Although the TST1 locus was strictly linked to resistance to M. tuberculosis infection and invokes mechanisms that precede T cell priming, the TST2 locus might modulate $\mathrm{T}$ cell responses that govern the intensity of the response in the PPD skin test.

HIV-infected resisters, who have an increased likelihood of having inadequate adaptive immune responses owing to $\mathrm{CD}^{+} \mathrm{T}$ cell depletion, might be particularly dependent on innate immune mechanisms for resistance to M. tuberculosis. As HIV and TB are co-prevalent in Uganda and Tanzania, this hypothesis was tested in a genome-wide association study of PPD reactivity in HIV-infected individuals, which found that a locus on chromosome 5 q31.1 was significantly associated with both binary (positive or negative in the PPD skin test; $P=1.22 \times 10^{-8}$ ) and quantitative (induration in millimetres; $P=1.45 \times 10^{-8}$ ) responses in the PPD skin test ${ }^{66}$. This region contains four genes, including the gene 
encoding IL-9, which is expressed and secreted by mast cells and Thelper $2\left(\mathrm{~T}_{\mathrm{H}} 2\right)$ cells and was previously associated with bronchial hyper-responsiveness. Interestingly, an inverse relationship between the incidence of asthma and TB was reported ${ }^{67,68}$, suggesting that IL-9 and its pleiotropic effects on lung inflammatory responses protect against $M$. tuberculosis infection. Although IL9 is an intriguing possible resistance gene, the other genes in the $5 \mathrm{q} 31.1$ region may also have a role in resistance to $M$. tuberculosis. The study also replicated associations in the regions previously identified in HIV-negative resisters (on chromosomes 2, 5 and 11; discussed previously), including susceptibility loci near TST1.

Together, these results suggest that the resister phenotype has polygenic variance; that is, many individual genetic variants each with small individual effects contribute additively to the phenotype. Although evidence to support broad epistatic effects on infectious disease susceptibility is lacking, gene pair interactions have been described in genome-wide analyses of susceptibility to $\mathrm{TB}^{69,70}$ and leprosy ${ }^{71}$. Nonetheless, the substantial overlap in the loci that are associated with the resister phenotype or in the results of PPD skin reactivity tests that was detected in independent analyses argues that evolutionary pressure has selected variants that protect against the initial M. tuberculosis infection, at least in geographical regions that are hyperendemic for $\mathrm{TB}$.

\section{Macrophage-mediated resistance}

After inhalation, aerosolized $M$. tuberculosis must navigate multiple intrinsic barriers in the upper airways, including airway mucins and ciliated epithelial cells. The bacterium then encounters resident alveolar macrophages, which exhibit pro-inflammatory and anti-inflammatory responses and are uniquely positioned to have a key role in mediating early clearance of M. tuberculosis ${ }^{72-74}$. The effector functions of alveolar macrophages might be modulated by neutrophils through, for example, their formation of neutrophil extracellular traps; however, the role of neutrophils in both microbicidal and immunopathological activities is complex and is reviewed elsewhere ${ }^{75,76}$. M. tuberculosis is recognized by multiple pattern recognition receptors (PRRs) at the cell surface or within the phagosome or by cytosolic PRRs after phagosomal rupture ${ }^{77,78}$. Subsequently, the outcome of infection depends on effective phagosome acidification, phagosome-lysosome fusion, $6 \mathrm{kDa}$ early secretory antigenic target (ESAT6) secretion system 1 (ESX1)-dependent escape of M. tuberculosis from the phagosome ${ }^{79}$, activation of the inflammasome (resulting in maturation of pro-IL- $1 \beta$ and pro-IL-18) ${ }^{78}$, upregulation of host genes that are either required for intracellular killing mechanisms (for example, reactive oxygen species, nitric oxide (produced by inducible nitric oxide synthase), cathelicidin antimicrobial peptide (CAMP ${ }^{80}$ and autophagy) or detrimental to the host (that is, IFN $\beta$ production following intracellular sensing of $M$. tuberculosis DNA by cyclic GMP-AMP synthase (cGAS) ${ }^{81,82}$ ) and, ultimately, the activation of host cell death pathways (for example, pyroptosis, apoptosis and necroptosis) ${ }^{83,84}$. Resistance alleles could modulate a number of these airway clearance functions or macrophage antimicrobial mechanisms (FIG. 2).
Inflammatory signalling pathways. Genetic regulation of inflammatory pathways is well described ${ }^{85-88}$, and some studies have associated susceptibility to mycobacterial infections with polymorphisms in Toll-like receptor (TLR) pathway components ${ }^{89-96}$, regulators of TLR function ${ }^{97,98}$, C-type lectin receptors ${ }^{99}$, autophagy proteins ${ }^{100,101}$ and other pathways for pro-inflammatory cytokine production ${ }^{102}$. However, only some of these studies define functional polymorphisms (that affect TLR expression or signalling, for example), and the identified associations with clinical phenotypes require replication in other populations. Interestingly, patients with Mendelian primary immunodeficiency of myeloid differentiation primary response 88 (MYD88) or IL-1 receptor-associated kinase 4 (IRAK4), which are central to most TLR signalling pathways, do not develop mycobacterial diseases ${ }^{103}$. Furthermore, few human genetic studies have found an association of resistance to $M$. tuberculosis infection (as opposed to susceptibility to disease) with polymorphisms in genes involved in any of these cellular pathways. A recently discovered single nucleotide polymorphism (rs5743854) in the promoter of the gene encoding TOLLIP is an expression QTL for which the G/G allele is associated with lower TOLLIP expression in monocytes and with increased risk of LTBI, pulmonary TB and meningeal $\mathrm{TB}^{63}$. Although the specific mechanisms through which high TOLLIP expression contributes to $M$. tuberculosis resistance as well as to protection from disease are not known, the known role of TOLLIP in directing autophagy and its negative regulation of TLR2, TLR4 and IL-1 receptor (IL-1R) suggest that these pathways are mechanisms of resistance. Although replication of the genetic association findings in independent cohorts is needed, the studies discussed above suggest that resistance alleles exist and may be relevant to the resister phenotype.

Autophagy. Autophagy limits intracellular survival of M. tuberculosis and maturation of the mycobacterial phagosome ${ }^{104,105}$. An in vitro genome-wide screen identified autophagy factors as the host factors that were most influential in restricting the intracellular growth of M. tuberculosis ${ }^{106}$. The M. tuberculosis ESX1 secretion system is required for autophagy initiation through cGAS-stimulator of interferon genes (STING)-triggered recruitment of microtubule-associated proteins $1 \mathrm{~A} / 1 \mathrm{~B}$ light chain 3 (MAP1LC3) to autophagosomes ${ }^{82,107,108}$, but ESX1 may also be involved in the impairment of autophagosome maturation ${ }^{109}$. Whether autophagy is involved in host protection versus virulence in the mouse model is controversial. Genetic deletion of the key autophagy factor Atg5 in mice results in more severe disease that correlates with both uncontrolled M. tuberculosis growth and exacerbated lung immunopathology ${ }^{110}$. However, this severe disease was later suggested to result from increased neutrophil recruitment in the autophagy protein 5 (ATG5)-deficient animals and not from defective autophagy ${ }^{111}$. Genetic variants within the autophagy pathway have been associated with TB in candidate-gene association studies ${ }^{100,101}$, but whether similar variants control LTBI risk is poorly studied. A recent candidate-gene association study found that 


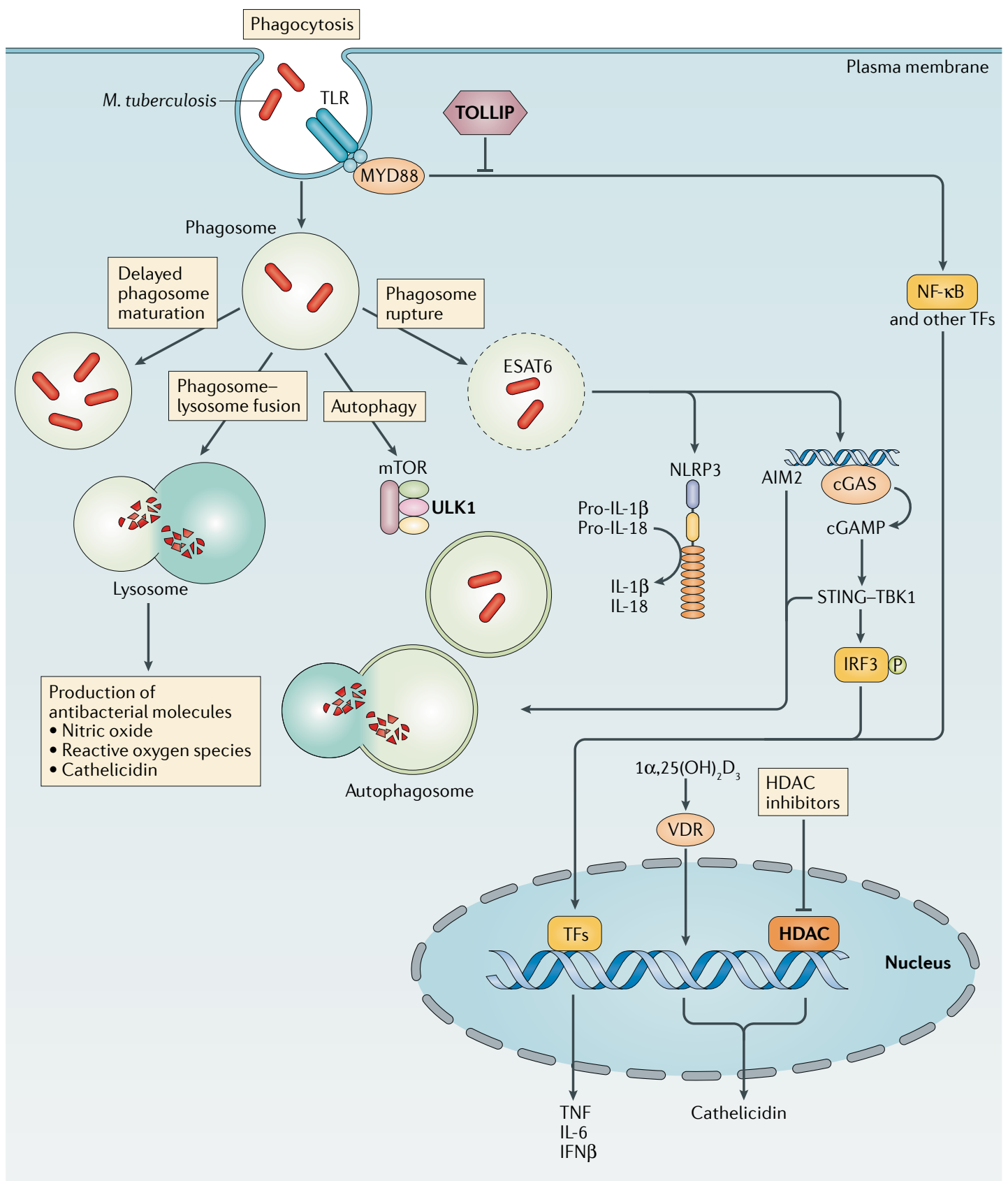

Fig. 2 | Macrophage-mediated resistance to Mycobacterium tuberculosis. Macrophages can provide resistance to Mycobacterium tuberculosis infection at multiple points in the infection process, including the initial uptake of bacilli into phagosomes and through any of the possible fates of these phagosomes. These fates include effective (versus delayed) phagosome maturation (resulting in the generation of microbicidal products, such as nitric oxide, reactive oxygen species and cathelicidin), fusion with the lysosome (resulting in degradation of the phagosomal contents), recruitment of autophagy factors (resulting ultimately in autophagosome-lysosome fusion) or phagosomal escape of bacteria into the cytosol. Pro-inflammatory cytokine production may result from Toll-like receptor (TLR) ligation or the recognition of signals following phagosomal rupture, including inflammasome-triggered maturation of pro-IL-1 $\beta$ or pro-IL-18 and recognition of cytosolic M. tuberculosis DNA by cyclic GMP-AMP synthase (cGAS) and the resultant stimulator of interferon genes (STING)-dependent interferon regulatory factor 3 (IRF3)-driven transcriptional response. Vitamin $D_{3}$ receptor (VDR)-dependent transcription, which requires prior activation of vitamin $D$ to $1 \alpha, 25(\mathrm{OH})_{2} \mathrm{D}_{3}$ through TLR or IFN $\gamma$ signalling events, results in cathelicidin expression. Genetic and cellular evidence exists for a role for the negative TLR regulator Toll-interacting protein (TOLLIP), the autophagy factor Unc51-like kinase 1 (ULK1) and histone deacetylases (HDACs; which are master transcriptional regulators) in resistance. AIM2, absent in melanoma 2; cGAMP, cyclic GMP-AMP; ESAT6, 6 kDa early secretory antigenic target; mTOR, mechanistic target of rapamycin; MYD88, myeloid differentiation primary response protein MYD88; NF- $\mathrm{BB}$, nuclear factor- $\mathrm{kB}$; NLRP3, NOD-, LRR- and pyrin domain-containing 3; TBK1, TANK-binding kinase 1; TFs, transcription factors;

TNF, tumour necrosis factor. 
two polymorphisms in $U L K 1$, which encodes a component of an upstream protein complex that transduces signals to central autophagy effectors, were associated with LTBI in Asian contacts of index cases ${ }^{62}$. After adjustment for clinical risk factors for LTBI, each of these ULK1 minor alleles was estimated to confer an $80 \%$ reduction in LTBI risk. This result might be due to an improvement in selective autophagy, decreased M. tuberculosis replication or increased TNF secretion in response to TLR ligands, as suggested from mechanistic studies using ULK1-deficient cells ${ }^{62}$.

Monocyte gene expression and histone deacetylase pathways. One hypothesis to explain the resistance to M. tuberculosis infection in the Uganda study ${ }^{12}$ is that following infection, the expression profiles of blood monocytes from individuals with LTBI and resisters are distinct. In a comparative transcriptional profiling study, monocytes from each clinical group were infected ex vivo with M. tuberculosis ${ }^{112}$, and the microarray data were analysed with Gene Set Enrichment Analysis (GSEA) ${ }^{113}$ to identify host pathways that are associated with each clinical phenotype (resister and LTBI) according to curated gene sets from transcriptional databases. The gene set that was most significantly associated with the resister group was from a previous study of sodium butyratestimulated cells ${ }^{114}$. Sodium butyrate is a short chain fatty acid that inhibits histone deacetylases (HDACs), which modify chromatin and regulate cellular function, including signalling pathways ${ }^{115,116}$. Interestingly, phenylbutyrate, a class I HDAC inhibitor that is known to synergize with vitamin D to induce CAMP production and inhibit $M$. tuberculosis growth in macrophages ${ }^{117}$, has been tested as a potential host-directed therapy for pulmonary $\mathrm{TB}^{118}$. Activated vitamin $\mathrm{D}\left(1 \alpha, 25(\mathrm{OH})_{2} \mathrm{D}_{3}\right)$ binds to the vitamin $\mathrm{D}_{3}$ receptor (VDR), which translocates to the nucleus to induce expression of CAMP and drive other host processes, including autophagy and autophagosome-lysosome fusion ${ }^{80}$. CAMP has direct antimicrobial activity against $M$. tuberculosis in the phagosomal compartment ${ }^{80}$. Together, these data suggest that monocytes from resisters and individuals with LTBI respond differently to ex vivo $M$. tuberculosis infection. Targeting HDACs with inhibitors might provide a novel therapeutic option for $M$. tuberculosis infections; however, the specific mechanisms by which HDAC-dependent pathways are altered in resisters, and whether epigenetic mechanisms or 'trained immunity' are involved, are unknown.

\section{T cell-mediated resistance}

Several lines of evidence from human studies and animal challenge models underscore the importance of $\mathrm{T}$ cells in controlling $M$. tuberculosis infection ${ }^{119-121}$. HIV-infected individuals with low $\mathrm{CD} 4^{+} \mathrm{T}$ cell counts have increased risk of progressing from LTBI to TB. In addition, patients with MSMD have defects in the IL-12-IFN $\gamma$ pathway and increased susceptibility to disseminated mycobacterial infections ${ }^{55}$. Furthermore, mouse models of acute $M$. tuberculosis infection have demonstrated the importance of IFN $\gamma$ production in controlling bacterial replication and survival ${ }^{122}$. However, the source of IFN $\gamma$ remains controversial, as its production by $\mathrm{CD} 4^{+} \mathrm{T}$ cells may be dispensable for control of $M$. tuberculosis infection in some mouse models ${ }^{14-16}$, whereas IFN $\gamma$ production is essential in other mouse models ${ }^{123}$. Furthermore, IFN $\gamma$-producing $\mathrm{CD} 4{ }^{+} \mathrm{T}$ cells have not emerged as an immunological correlate of protection from infection in humans, which suggests that this profile is important but is not sufficient for protection against $M$. tuberculosis infection ${ }^{124,125}$. In individuals with LTBI, MHC-restricted $\alpha \beta$ T cells recognize a broad repertoire of $\mathrm{MHC}$ class I-restricted and $\mathrm{MHC}$ class II-restricted $M$. tuberculosis peptides and exemplify a classical $\mathrm{T}_{\mathrm{H}} 1$ cell-like response. Implicit in their definition, resisters lack reactivity in the PPD skin test or secretion of IFN $\gamma$ by $\mathrm{T}$ cells following antigen stimulation, although, hypothetically, these individuals might have IFN $\gamma$ independent $\mathrm{T}$ cell responses that mediate resistance to M. tuberculosis or its clearance.

IFN $\gamma$-independent $\mathrm{T}$ cell responses. IFN $\gamma$-independent $\mathrm{T}$ cell responses to mycobacterial antigens have been described (FIG. 3). For example, Cambodian patients with pulmonary TB who remained anergic to PPD following treatment completion displayed tuberculin antigenspecific $\mathrm{T}$ cell responses in vitro that were characterized by the production of IL-10 rather than IFN $\gamma^{126,127}$. IL-10, which is known for its anti-inflammatory role in mitigating $\mathrm{T}_{\mathrm{H}} 1$ cell responses to minimize the potentially deleterious effects of TNF and IFN $\gamma$, is mostly implicated in the immune response to TB, and no evidence exists for a protective role of IL-10 in the early stages of M. tuberculosis infection ${ }^{128}$. However, a genotyping study in Ghana found that individuals with the IL10 promoter haplotype with the highest association with low circulating levels of IL-10 were more likely to have TB or be PPD-positive than to be PPD-negative ${ }^{129}$. Whether high IL-10 levels in these individuals truly confer resistance to infection, as opposed to PPD-specific anergy in the presence of LTBI, remains to be determined.

Additional $\mathrm{CD}^{+} \mathrm{T}$ cell subsets, including $\mathrm{T}_{\mathrm{H}} 17$ cells, could contribute to the resister phenotype through IFN $\gamma$-independent mechanisms. In mice, the production of IL-17A, one of several $\mathrm{T}_{\mathrm{H}}$ 17-related cytokines, recruits neutrophils and other inflammatory cells to the lung and is involved in granuloma maturation ${ }^{130}$. Adoptive transfer of BCG-specific $\mathrm{T}_{\mathrm{H}} 17$ cells harvested from immunized IFN $\gamma$-deficient mice into recipient $\mathrm{V}(\mathrm{D}) \mathrm{J}$ recombination-activating protein (RAG)-deficient mice gave these recipient mice a survival advantage when challenged with $M$. tuberculosis, which was comparable to that seen with transfer of $\mathrm{T}_{\mathrm{H}} 1$ cells from IFN $\gamma$-competent mice ${ }^{131}$. This IFN $\gamma$ independent partial protection provided by $\mathrm{T}_{\mathrm{H}} 17$ cells against $M$. tuberculosis was also seen in another adoptive transfer model ${ }^{132}$. Unlike IL-10, IL-17 is not known to directly interfere with IFN $\gamma$ production, and whether these IFN $\gamma$-independent $\mathrm{T}_{\mathrm{H}} 17$ activities are relevant to the resister phenotype is unknown. However, taken together, these examples illustrate that despite having persistent negative responses in PPD skin reactivity tests and IGRAs, it is possible that resisters have other mycobacteria-specific MHC class I-restricted or MHC class II-restricted $\mathrm{T}$ cell responses. 


\section{LTBI}

NTM and other microorganisms
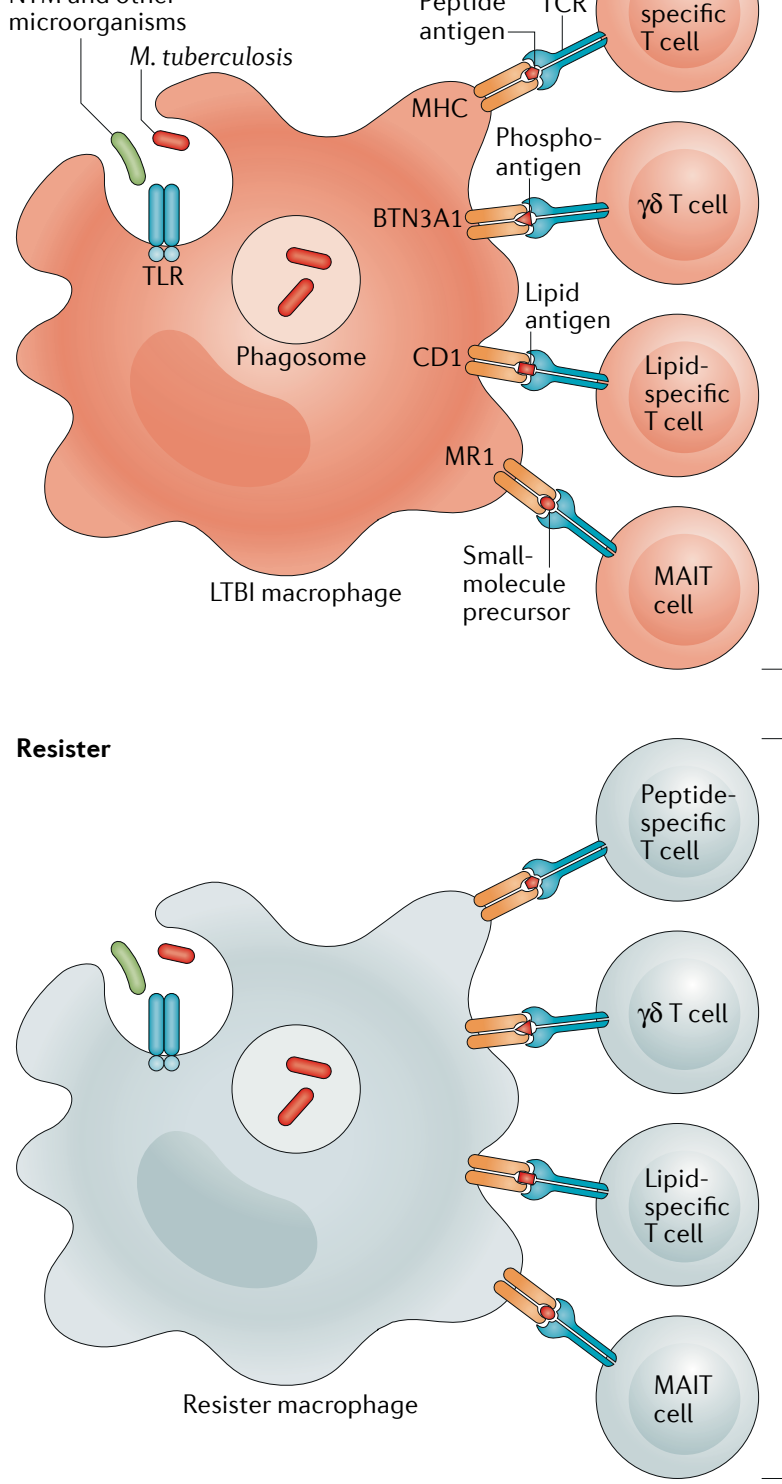
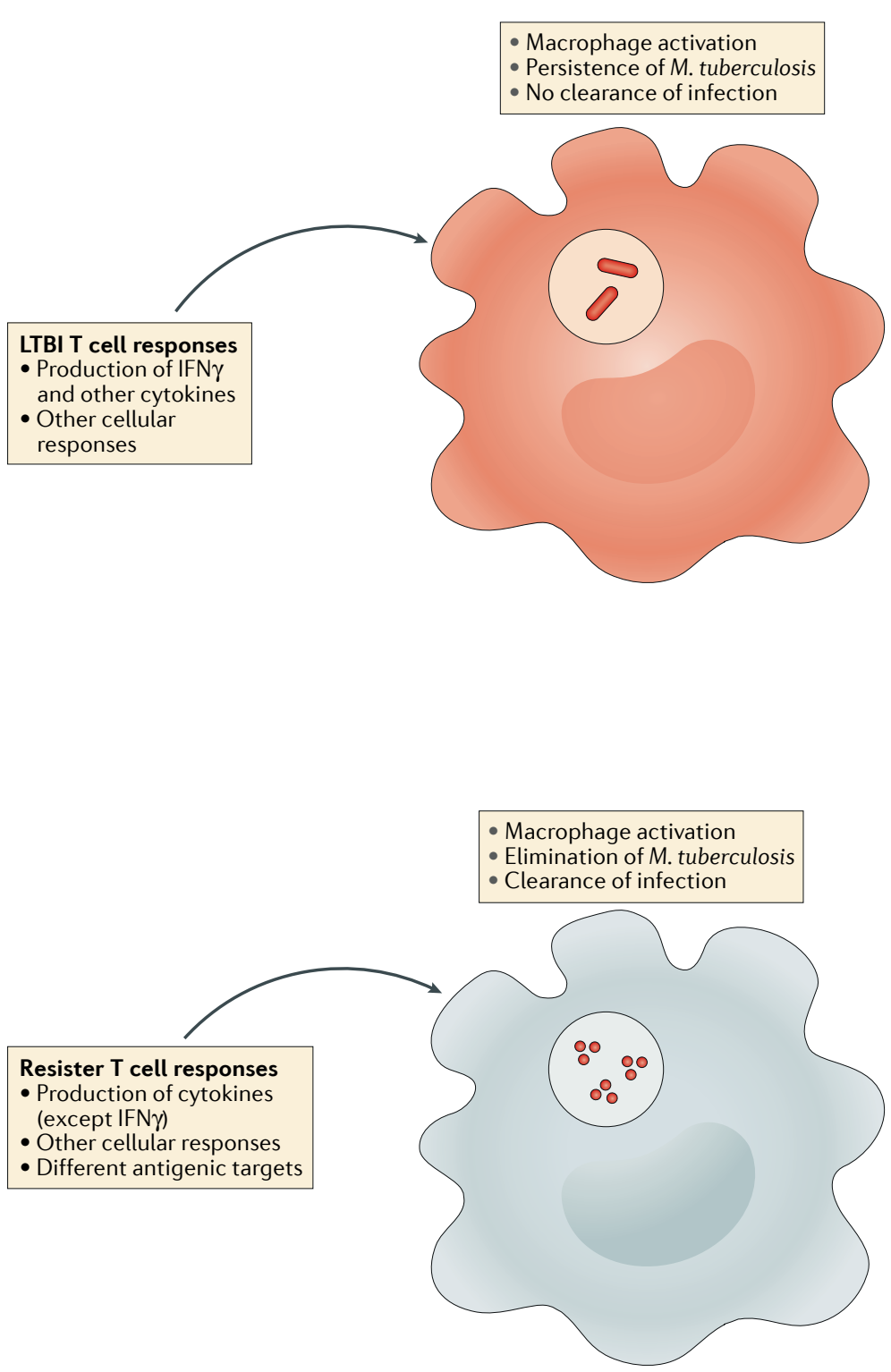

Fig. 3 | T cell-mediated resistance to Mycobacterium tuberculosis. After phagocytosis of Mycobacterium tuberculosis by macrophages and dendritic cells (not shown), various T cell responses are stimulated, including conventional MHCrestricted responses (peptide-specific T cells) and MHC-independent responses ( $\gamma \delta$ T cells, which detect phosphorylated prenyl metabolites (also known as phosphoantigens)), CD1-restricted (lipid-specific) T cells and MHC class I-related gene protein (MR1)-restricted T cells (also known as mucosal-associated invariant T (MAIT) cells); MR1 presents small molecules, such as vitamin $\mathrm{B}_{2}$ derivatives. Production of IFN $\gamma$ by $C D 4^{+} T$ cells is a hallmark of the $T$ cell response in individuals with latent M. tuberculosis infection (LTBI), whereas by definition, 'resisters' lack this IFN $\gamma$ response. Qualitative differences in T cell responses between resisters and individuals with LTBI lead to the production of different macrophage-activating cytokines and chemokines, resulting in either the elimination of $M$. tuberculosis by resisters or persistence of $M$. tuberculosis in individuals with LTBI. BTN3A1, butyrophilin subfamily 3 member A1; NTM, non-tuberculous mycobacteria; TCR, T cell receptor; TLR, Toll-like receptor.

Unconventional T cell responses. In addition to mycobacterial protein antigens, $\mathrm{T}$ cells also recognize nonprotein mycobacterial antigens (FIG. 3). For example, $\mathrm{T}$ cells are activated by mycobacterial cell wall lipids that are bound to CD1 proteins, which are homologous to MHC class I molecules but are functionally nonpolymorphic ${ }^{40,133,134}$. The human CD1 locus encodes four proteins (CD1A-CD1D) that are localized at the cell surface and present lipid antigens to $\mathrm{T}$ cells. In a cross-sectional study of South African adolescents with or without LTBI, there were low intra-donor correlations between $\mathrm{T}$ cell responses to protein and lipid antigens ${ }^{135}$, indicating that $\mathrm{T}$ cell responses to lipid antigens are not redundant with those to protein antigens and that the responses to the different antigens could be complementary. Immunity to lipid antigens could be primed by exposure in early life to non-tuberculous mycobacteria, which could facilitate clearance of M. tuberculosis 
following infection, thus limiting the initiation of peptide-specific $\mathrm{T}$ cell responses that are mostly responsible for producing a positive result in the PPD skin test. In addition, lipid-specific $\mathrm{T}$ cells could also be primed by vaccination with BCG. Functionally, T cells specific for mycobacterial lipids have been shown to have a $T_{H} 1$ cell cytokine-producing profile ex vivo, supporting their role in the clearance of $M$. tuberculosis-infected cells ${ }^{136}$.

The MHC class I-related gene protein (MR1) antigenpresenting molecule presents small molecules instead of peptides or lipids to T cells ${ }^{137}$ and is important for the development of mucosal-associated invariant T (MAIT) cells ${ }^{138-140}$. MAIT cells can kill M. tuberculosis-infected cells in an MR1-dependent manner ${ }^{41}$, and Mr1-knockout mice have a higher lung burden of $M$. bovis BCG than wild-type mice ${ }^{141}$. Furthermore, in candidate-gene association studies, $M R 1$ and $C D 1$ polymorphisms were associated with susceptibility to $\mathrm{TB}^{142,143}$. Finally, $\gamma \delta$ $\mathrm{T}$ cells are a $\mathrm{T}$ cell lineage that express a heterodimeric $T$ cell receptor and are activated by phosphorylated prenyl metabolites ${ }^{144,145}$. V $\gamma 9 \mathrm{~V} \delta 2 \mathrm{~T}$ cells are activated by BCGinfected cells and can lyse BCG-infected target cells ${ }^{146}$.

Thus, in PPD-negative individuals, the CD1-specific, MR1-specific and $\gamma \delta$ T cell populations might provide cellular immunity against $M$. tuberculosis that is independent of the IFN $\gamma$ production by $\mathrm{PPD}$-specific $\mathrm{CD} 4^{+}$ $\mathrm{T}$ cells that defines LTBI. Further study is required to determine whether these other populations of $\mathrm{T}$ cells protect against $M$. tuberculosis infection in resisters or, alternatively, whether these $\mathrm{T}$ cells prevent progression of LTBI in individuals who are unable to produce IFN $\gamma$ in response to $M$. tuberculosis antigens.

\section{B cell-mediated resistance}

Antibodies are powerful mediators of protective immunity against many infectious diseases, and stimulating their production is the goal of vaccination strategies ${ }^{147,148}$. In M. tuberculosis infection and disease, however, the role of humoral immunity is probably complex and remains unclear ${ }^{149,150}$. Passive transfer of antibodies has not consistently conferred protection ${ }^{151-154}$, and immunoglobulin $\mathrm{G}$ (IgG)-deficient individuals do not exhibit reduced control of bacterial infections ${ }^{155}$. By contrast, a post hoc analysis of the MVA85A vaccine trial found that elevated Ag85A-specific IgG titres correlated with protection against $\mathrm{TB}^{156}$. In addition, depletion of $\mathrm{B}$ cells in a non-human primate model of $M$. tuberculosis infection resulted in increased lesional bacterial burden $^{157}$. Furthermore, in patients with active TB, B cell function is initially abnormal but returns to normal after successful treatment ${ }^{158,159}$. These observations highlight the immunoregulatory role of B cells in controlling M. tuberculosis infections, which extends beyond their direct antibody-mediated effector functions (FIG. 4).

Antibodies and latent Mycobacterium tuberculosis infection. Antibodies, plasma cells and antibody-responsive innate immune cells that express crystallizable fragment $(\mathrm{Fc})$ receptors are abundant in M. tuberculosis granulomas ${ }^{160,161}$, indicating that these

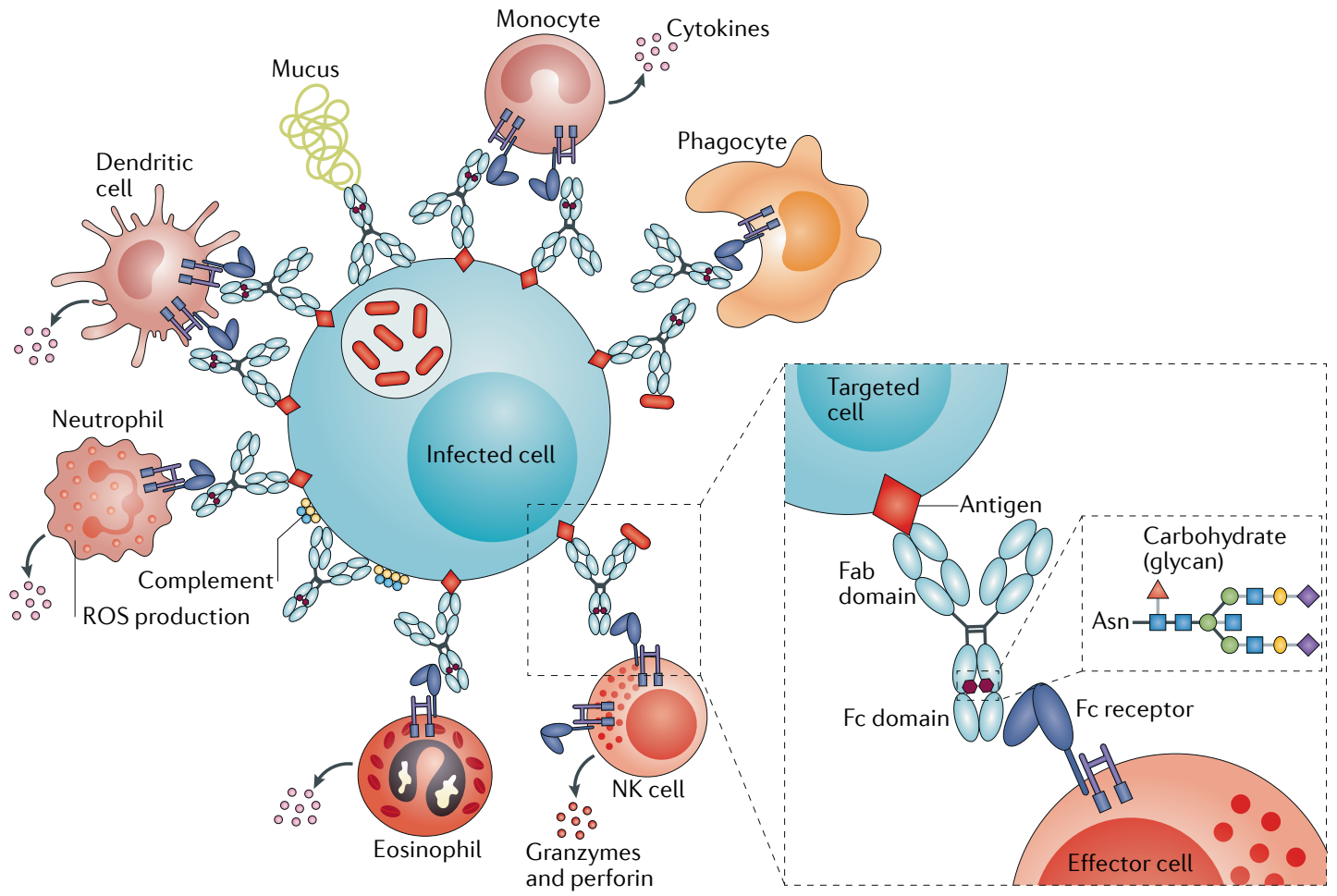

Fig. 4 | Antibody-mediated resistance to Mycobacterium tuberculosis. Beyond their role in clearing pathogens, antibodies also direct the rapid destruction of infected cells via the recruitment of innate immune cells (such as phagocytes) that express crystallizable fragment ( $\mathrm{Fc}$ ) receptors. Two modifications to the Fc domain of an antibody control its affinity for Fc receptors, namely, changes in the antibody subclass or isotype and its glycosylation. Fab, antigen-binding fragment; NK cell, natural killer cell; ROS, reactive oxygen species. 
innate immune cells are actively recruited and might potentially contribute to antimicrobial activity ${ }^{162,163}$. Distinct Fc effector profiles were observed in individuals with LTBI versus those with active disease. Individuals with LTBI had improved antibody functionality that was linked to elevated binding to the lowaffinity immunoglobulin- $\gamma$ Fc region receptor III-A $(\mathrm{Fc} \gamma \mathrm{R} 3 \mathrm{~A})^{164}$, which is highly expressed by natural killer cells, neutrophils, mature macrophages and dendritic cells ${ }^{163}$. Furthermore, these antibodies not only improved innate immune cell activity but also contributed to the restriction of intracellular survival of $M$. tuberculosis in previously infected primary macrophages. Interestingly, this differential functional activity was not related to altered subclass selection but was instead related to substantial changes in antibody glycosylation among the M. tuberculosis-infected individuals ${ }^{164}$.

Antibodies and the resister phenotype. It is unclear whether antibodies contribute to the resister phenotype, but it is plausible that at the time of repeated M. tuberculosis exposure that pre-existing antibodies might direct the antimicrobial activity of macrophages, neutrophils or dendritic cells to eliminate the bacteria more effectively. Although in vitro studies indicate a limited role for antibody-mediated opsonophagocytic prevention of macrophage infection by $M$. tuberculosis, the addition of pooled IgG derived from individuals with LTBI to previously infected healthy donor primary macrophages can drive bacterial elimination by a process that probably involves activation of the inflammasome ${ }^{164}$. These results suggest that, in addition to their minor role in limiting initial infection through opsonization, antibodies 'cure' infected macrophages if they are present at the right time and place. Although the majority of healthy donor macrophages restricted $M$. tuberculosis survival in the presence of pooled IgG from individuals with LTBI $^{164}$, the level of restriction varied by macrophage donor, which suggests that antibody-mediated killing of M. tuberculosis is also dependent on factors that are intrinsic to innate immune cells.

Thus, whether natural or affinity-matured humoral immunity exists among resisters is unknown, but humoral immunity might provide an exciting novel immunological axis that links the adaptive and innate immune responses to target and eradicate $M$. tuberculosis after exposure and warrants further exploration.

\section{Conclusions and outlook}

Historically, significant breakthroughs in treating infectious diseases have been made by studying mechanisms of resistance rather than susceptibility to infections. The most notable historical example is the observation that milkmaids exposed to cowpox were resistant to smallpox $^{165}$. A more contemporary example is the HIV resistance of individuals with a variant of CCR5, CCR $5 \Delta 32$ $\left(\mathrm{REFS}^{166,167}\right)$. Both these observations led to transformative therapeutic interventions - the smallpox vaccine and CCR5 inhibitors, respectively ${ }^{168}$.

For much of the past century, many investigators have postulated that some individuals are naturally resistant to $M$. tuberculosis infection in the face of intense exposure. However, a number of challenges have impeded the elucidation of potential resistance mechanisms, including the limitations of using an indirect immunological test to define the resister phenotype and the need to incorporate measurements of exposure intensity in study designs. Despite this, contemporary epidemiological evidence supports the existence of resisters. Genome-wide association analysis of data from independent studies has identified loci that are associated with resistance to $M$. tuberculosis infection. The elucidation of immunological and genetic mechanisms of the resister phenotype is at an early stage, but these studies might reveal heterogeneous protective responses that are relevant to different types of resisters. For example, macrophage-dependent pathways that prevent bacterial uptake or rapidly clear M. tuberculosis before the development of an adaptive immune response define innate resisters. Alternatively, adaptive resisters are individuals in which $\mathrm{T}$ cell and $\mathrm{B}$ cell effector functions eliminate or restrict $M$. tuberculosis infections, either independently of IFN $\gamma$ production or through priming by non-protein antigens. Further study is required to clarify whether adaptive resisters have greater resistance to progression to active TB than individuals with traditionally defined LTBI; however, these studies could identify novel correlates of immune protection or aid current prognostic efforts to stratify those individuals who are most at risk of disease progression ${ }^{4,5}$.

Looking ahead, integrated research approaches using advanced epidemiological, genetic and immunological tools will be required to dissect mechanisms of resistance. In future studies, features of an optimally defined resister should incorporate several variables outlined in BOX 1 , including, first, indices of exposure (both intensity and duration) using, at a minimum, validated epidemiological risk scoring ${ }^{12,13}$; second, the use of both the PPD skin reactivity test and the IGRA to avoid misclassification bias resulting from discordant immunological tests; and third, longitudinal sampling for serial LTBI testing.

Epidemiological risk scores must include an assessment of the nature of contact between the index case or cases and the exposed individual (that is, whether the index case is the primary caregiver and the frequency and proximity of contact) and some assessment of infectivity of the exposure environment (for example, whether the index case is coughing, whether their sputum is smear-positive for M. tuberculosis and whether there are multiple index cases within a household or employment setting). Although not yet ready for practical implementation, more advanced assessments of infectious risk, such as aerobiological environmental sampling where transmission risk has been correlated with the degree of ventilation and with the number of viable bacteria sampled from cough aerosols, could be incorporated in future studies ${ }^{37,169,170}$.

Even in areas of high TB endemicity, some level of discordance exists between the results of PPD skin reactivity tests and IGRAs ${ }^{171}$. Consequently, individuals with discordant results in the PPD skin reactivity test and the IGRA are not categorized as resisters, although retaining clinical samples from these individuals is important to facilitate studies to better understand the mechanistic 
basis of this discordance. As the resister category might encompass multiple biological phenotypes, at this early stage in their characterization, we favour more stringent criteria to avoid misclassification, which justifies the increased expense and logistical complexity of implementing multiple testing modalities (PPD skin reactivity tests and IGRAs) and serial testing. Longitudinal sampling should include, at a minimum, multiple LTBI diagnostic tests in the year following initial exposure, as most but not all conversions occur in the first 3 months following exposure ${ }^{36}$. In circumstances in which resisters remain in regions of high $M$. tuberculosis transmission, follow-up testing may be warranted to ensure that any new conversions owing to community exposures are detected.

Advances in the past decade have transformed genetic methods and platforms, which now include affordable and standardized genome-wide detection of polymorphisms. These tools provide assessment of polymorphisms that are annotated in public databases. Whole-genome sequencing is also more affordable and can be used to examine resisters for unidentified polymorphisms that are not annotated in public databases. To address limitations in the availability of patient samples, new advances in stem cell work (for example, induced pluripotent stem cells derived from peripheral blood mononuclear cells) have made possible the creation of permanent cell lines from individuals, which can be differentiated into different cell types that are more relevant for studying $M$. tuberculosis pathogenesis (for example, alveolar macrophages). Finally, if $M$. tuberculosis cultures from index cases are available, comparisons of strain type, host phenotype (resister versus LTBI versus TB) and host genotype, as well as determination of whether transmission events are sympatric or allopatric ${ }^{172}$, are exciting avenues of investigation.

The integration of rigorous epidemiological phenotyping with mechanistic studies that investigate global immune pathways in macrophages, T cells and B cells, and how these pathways might differ between resisters and individuals with LTBI, should provide further biological insight into the mechanisms of early clearance or prevention of infection by M. tuberculosis. These potential biological mechanisms should provide targets for drugs and vaccines that could improve specific immune functions and improve therapeutic options for treating TB.

\section{Published online 12 June 2018}

1. Dye, C., Scheele, S., Dolin, P., Pathania, V. \& Raviglione, M. C. Consensus statement. Global burden of tuberculosis: estimated incidence, prevalence, and mortality by country. WHO global surveillance and monitoring project. JAMA 282, 677-686 (1999).

2. Houben, R. M. \& Dodd, P. J. The global burden of latent tuberculosis infection: a re-estimation using mathematical modelling. PLoS Med. 13, e 1002152 (2016).

3. World Health Organization. Global Tuberculosis Report 2017. (WHO, 2017).

4. Thompson, E. G. et al. Host blood RNA signatures predict the outcome of tuberculosis treatment. Tuberculosis 107, 48-58 (2017).

5. Zak, D. E. et al. A blood RNA signature for tuberculosis disease risk: a prospective cohort study. Lancet 387, 2312-2322 (2016).

6. Esmail, H. et al. Characterization of progressive HIVassociated tuberculosis using 2-deoxy-2-[18F]fluoroD-glucose positron emission and computed tomography. Nat. Med. 22, 1090-1093 (2016).

7. Barry, C. E. 3rd et al. The spectrum of latent tuberculosis: rethinking the biology and intervention strategies. Nat. Rev. Microbiol. 7, 845-855 (2009).

8. Pai, M. \& Behr, M. Latent Mycobacterium tuberculosis infection and interferon-gamma release assays. Microbiol. Spectr. https://doi.org/10.1128/ microbiolspec.TBTB2-0023-2016 (2016).

9. Mendel, F. Die von Pirquet'sche Hautreaktion und die intravenöse Tuberkulinbehandlung. Med. Klin. 4 , 402-404 (1908)

10. Seibert, F. B. History of the development of purified protein derivative tuberculin. Am. Rev. Tuberc 44, 1-8 (1941).

11. Yang, H., Kruh-Garcia, N. A. \& Dobos, K. M. Purified protein derivatives of tuberculin - past, present, and future. FEMS Immunol. Med. Microbiol. 66, 273-280 (2012).

12. Ma, N. et al. Clinical and epidemiological characteristics of individuals resistant to $M$. tuberculosis infection in a longitudinal TB household contact study in Kampala. BMC Infect. Dis. 14, 352 (2014).

13. Mandalakas, A. M. et al. Well-quantified tuberculosis exposure is a reliable surrogate measure of tuberculosis infection. Int. J. Tuberc Lung Dis. 16, 1033-1039 (2012)

14. Cowley, S. C. \& Elkins, K. L. CD4+ T cells mediate IFN-gamma-independent control of Mycobacterium tuberculosis infection both in vitro and in vivo. J. Immunol. 171, 4689-4699 (2003)

15. Sakai, S. et al. CD4 T cell-derived IFN-gamma plays a minimal role in control of pulmonary Mycobacterium tuberculosis infection and must be actively repressed by PD-1 to prevent lethal disease. PLoS Pathog. 12, e1005667 (2016)

16. Smith, C. M. et al. Tuberculosis susceptibility and vaccine protection are independently controlled by host genotype. mBio 7, e01516 (2016).

17. Houk, V. N., Baker, J. H., Sorensen, K. \& Kent, D. C. The epidemiology of tuberculosis infection in a closed environment. Arch. Environ. Health 16, 26-35 (1968).

18. Morrison, J., Pai, M. \& Hopewell, P. C. Tuberculosis and latent tuberculosis infection in close contacts of people with pulmonary tuberculosis in low-income and middle-income countries: a systematic review and meta-analysis. Lancet Infect. Dis. 8, 359-368 (2008). This is a systematic review and meta-analysis of historical and contemporary case-contact studies that finds that $51.4 \%$ of individuals with a TB household contact have LTBI, although substantial study heterogeneity exists that likely reflects differing exposure intensities across studies and/or participants.

19. Amberson, J. B. \& Riggins, H. Tuberculosis among student nurses: a five year study at Bellevue hospital. Ann. Intern. Med. 10, 156-165 (1936).

20. Daniels, M. Primary tuberculous infection in nurses: manifestations and prognosis. Lancet 244, 201-204 (1944).

21. Aziz, A., Ishaq, M. \& Akhwand, R. Infection risk of sputum positive tuberculosis patients to their family contacts with and without chemotherapy. J. Pak. Med. Assoc. 35, 249-252 (1985)

22. Devadatta, S. et al. Attack rate of tuberculosis in a 5 -year period among close family contacts of tuberculous patients under domiciliary treatment with isoniazid plus PAS or isoniazid alone. Bull. World Health Organ. 42, 337-351 (1970).

23. Lemos, A. C., Matos, E. D., Pedral-Sampaio, D. B. \& Netto, E. M. Risk of tuberculosis among household contacts in Salvador, Bahia. Braz. J. Infect. Dis. 8 424-430 (2004).

24. Hill, P. C. et al. Longitudinal assessment of an ELISPOT test for Mycobacterium tuberculosis infection. PLoS Med. 4, e192 (2007).

25. Aguilar, D. et al. Mycobacterium tuberculosis strains with the Beijing genotype demonstrate variability in virulence associated with transmission. Tuberculosis 90, 319-325 (2010).

26. Parwati, I., van Crevel, R. \& van Soolingen, D. Possible underlying mechanisms for successful emergence of the Mycobacterium tuberculosis Beijing genotype strains. Lancet Infect. Dis. 10, 103-111 (2010).

27. Merker, M. et al. Evolutionary history and global spread of the Mycobacterium tuberculosis Beijing lineage. Nat. Genet. 47, 242-249 (2015).
28. Churchyard, G. J. et al. A trial of mass isoniazid preventive therapy for tuberculosis control. N. Engl. J. Med. 370, 301-310 (2014).

29. Cowie, R. L. Short course chemoprophylaxis with rifampicin, isoniazid and pyrazinamide for tuberculosis evaluated in gold miners with chronic silicosis: a double-blind placebo controlled trial. Tuber Lung Dis. 77, 239-243 (1996).

30. Vynnycky, E. et al. Tuberculosis control in South African gold mines: mathematical modeling of a trial of community-wide isoniazid preventive therapy. Am. J. Epidemiol. 181, 619-632 (2015).

31. Hanifa, Y. et al. Prevalence of latent tuberculosis infection among gold miners in South Africa. Int. J. Tuberc Lung Dis. 13, 39-46 (2009).

32. Wallis, R. S. Mathematical models of tuberculosis reactivation and relapse. Front. Microbiol. 7, 669 (2016).

This study presents a Markov model that uses published estimates of annual risk of acquiring $M$. tuberculosis infection to estimate the probability that an induration of $0 \mathrm{~mm}$ in the PPD skin reactivity test indicates a true resister and finds that this value is $22 \%$ in South African non-miners and $93 \%$ in gold miners.

33. World Health Organization. Global tuberculosis report 2015, 20th ed. WHO http://apps.who.int/iris/ handle/10665/191102 (2015).

34. Whalen, C. C. et al. Secondary attack rate of tuberculosis in urban households in Kampala, Uganda. PLoS ONE 6, e16137 (2011).

35. Stein, C. M., Hall, N. B., Malone, L. L. \& Mupere, E. The household contact study design for genetic epidemiological studies of infectious diseases. Front. Genet. 4, 61 (2013).

36. Stein, C. M. et al. Resistance and susceptibility to Mycobacterium Tuberculosis infection and disease in tuberculosis households in Kampala, Uganda. Am. J. Epidemiol. https://doi.org/10.1093/aje/kwx380 (2018).

This study of 872 households containing individuals with TB in Uganda monitors these individuals for $\geq 2$ years and finds that $\sim 10 \%$ of household contacts are resisters.

37. Andrews, J. R., Morrow, C. \& Wood, R. Modeling the role of public transportation in sustaining tuberculosis transmission in South Africa. Am. J. Epidemiol. 177, 556-561 (2013).

38. Classen, C. N. et al. Impact of social interactions in the community on the transmission of tuberculosis in a high incidence area. Thorax 54, 136-140 (1999).

39. Verver, S. et al. Proportion of tuberculosis transmission that takes place in households in a 
high-incidence area Lancet $363,212-214$ (2004).

40. Beckman, E. M. et al. Recognition of a lipid antigen by CD1-restricted alpha beta+ T cells. Nature 372 691-694 (1994)

41. Gold, M. C. et al. Human mucosal associated invariant T cells detect bacterially infected cells. PLoS Biol. 8 , e1000407 (2010)

42. Tanaka, Y. et al. Natural and synthetic non-peptide antigens recognized by human gamma delta T cells. Nature 375, 155-158 (1995).

43. Matos, D. S. et al. Differential interferon- gamma production characterizes the cytokine responses to Leishmania and Mycobacterium leprae antigens in concomitant mucocutaneous leishmaniasis and lepromatous leprosy. Clin. Infect. Dis. 40, e5-12 (2005)

44. Heimbeck, J. Incidence of tuberculosis in young adult women, with special reference to employment. Br. J. Tuberc. 32, 154-166 (1938).

45. Israel, H. L., Hetherington, H. W. \& Ord, J. G. A study of tuberculosis among students of nursing. JAMA 117 839-844 (1941).

46. Menzies, D. Interpretation of repeated tuberculin tests. Boosting, conversion, and reversion. Am. J. Respir. Crit. Care Med. 159, 15-21 (1999).

47. Chaussé, P. Nouvelles recherches sur la contagion de la tuberculose par l'air expiré pendant la toux. Ann. Inst. Pasteur 30, 613-641 (1916).

48. Lange, B. Die Epidemiologie der Tuberkulose Zentralblatt für bakteriologie, parasitenkunde und infektionskrankheiten 127, 25-46 (1933).

49. Dean, M. et al. Genetic restriction of HIV-1 infection and progression to AIDS by a deletion allele of the CKR5 structural gene. hemophilia growth and development study, multicenter AIDS cohort study, multicenter hemophilia cohort study, San Francisco city cohort, ALIVE Study. Science 273, 1856-1862 (1996).

50. Lindesmith, L. et al. Human susceptibility and resistance to Norwalk virus infection. Nat. Med. 9 548-553 (2003)

51. Lindesmith, L. C. et al. Mechanisms of GII.4 norovirus persistence in human populations. PLoS Med. 5, e31 (2008).

52. Miller, L. H., Mason, S. J., Clyde, D. F. \& McGinniss, M. H. The resistance factor to Plasmodium vivax in blacks. The Duffy-blood-group genotype, FyFy. N. Engl. J. Med. 295, 302-304 (1976).

53. Comstock, G. W. Tuberculosis in twins: a re-analysis of the Prophit survey. Am. Rev. Respir. Dis. 117 621-624 (1978)

54. Kallmann, F. \& Reisner, D. Twin studies on the significance of genetic factors in tuberculosis. Am. Rev. Tuberc. 47, 549-574 (1943)

55. Casanova, J.-L. \& Abel, L. Genetic dissection of immunity to mycobacteria: the human model. Annu. Rev. Immunol. 20, 581-620 (2002).

56. Hill, A. V. Aspects of genetic susceptibility to human infectious diseases. Annu. Rev. Genet. 40, 469-486 (2006).

57. Stein, C. M. et al. Genome scan of M. tuberculosis infection and disease in Ugandans. PLOS ONE 3 , e4094 (2008).

In this study, a genome scan identifies two loci (chromosome 2q21-22q24 and chromosome 5p13-15q22) that are linked to the resister phenotype; the latter locus overlaps with a region that was associated with the intensity of reactivity in the PPD skin test (that is, induration in millimetres) in an independent cohort study (reference 64).

58. Thye, T. et al. Genome-wide association analyses identifies a susceptibility locus for tuberculosis on chromosome 18q11.2. Nat. Genet. 42, 739-741 (2010).

This analysis of a large population $(11,425$ patients $)$ from two independent genome-wide association studies comparing patients with TB and healthy individuals identifies a SNP (on chromosome $18 q 11.2$ ) that is associated with TB susceptibility which demonstrates that non-MHC susceptibility loci can be identified, even in populations with high genetic diversity, when the sample size is increased by combining data from multiple studies.

59. Azad, A. K., Sadee, W. \& Schlesinger, L. S. Innate immune gene polymorphisms in tuberculosis. Infect. Immun. 80, 3343-3359 (2012).

60. Tosh, K. et al. Variants in the SP110 gene are associated with genetic susceptibility to tuberculosis in West Africa. Proc. Natl Acad. Sci. USA 103 10364-10368 (2006).
61. Sepulveda, R. L. et al. Evaluation of tuberculin reactivity in BCG-immunized siblings. Am. J. Respir. Crit. Care Med. 149, 620-624 (1994).

62. Horne, D. J. et al. Human ULK1 Variation and susceptibility to Mycobacterium tuberculosis infection. J. Infect. Dis. 214, 1260-1267 (2016).

63. Shah, J. A. et al. A functional TOLLIP variant is associated with BCG-specific immune responses and tuberculosis. Am. J. Respir. Crit. Care Med. 196, 502-511 (2017)

This study identifies a SNP in the promoter region of TOLLIP that reduces the expression of TOLLIP (a negative regulator of signalling through TLR2, TLR4 and IL-1R) and finds that this polymorphism is associated with increased risk of LTBI in M. tuberculosis-exposed individuals

64. Cobat, A. et al. Two loci control tuberculin skin test reactivity in an area hyperendemic for tuberculosis. J. Exp. Med. 206, 2583-2591 (2009).

This study carries out a genome-wide linkage analysis in South Africans and identifies two loci that are associated with a negative result in the PPD skin reactivity test; one of these loci has been subsequently linked to a SNP that is associated with TNF production (see reference 65 ).

65. Cobat, A. et al. Identification of a major locus, TNF1 that controls BCG-triggered tumor necrosis factor production by leukocytes in an area hyperendemic for tuberculosis. Clin. Infect. Dis. 57, 963-970 (2013).

66. Sobota, R. S et al. A chromosome $5 q 31.1$ locus associates with tuberculin skin test reactivity in HIV-positive individuals from tuberculosis hyper-endemic regions in east Africa. PLoS Genet. 13 e1006710 (2017).

67. von Hertzen, L., Klaukka, T., Mattila, H. \& Haahtela, T. Mycobacterium tuberculosis infection and the subsequent development of asthma and allergic conditions. J. Allergy Clin. Immunol. 104, 1211-1214 (1999).

68. von Mutius, E et al. International patterns of tuberculosis and the prevalence of symptoms of asthma, rhinitis, and eczema. Thorax 55, 449-453 (2000).

69. Daya, M., van der Merwe, L., van Helden, P. D., Moller, M. \& Hoal, E. G. Investigating the role of gene-gene interactions in TB susceptibility. PLOS ONE 10, e0123970 (2014).

70. Stein, C. M. et al. Genomics of human pulmonary tuberculosis: from genes to pathways. Curr. Genet. Med. Rep. 5, 149-166 (2017).

71. Zhang, F. et al. Identification of two new loci at IL23R and RAB32 that influence susceptibility to leprosy. Nat. Genet. 43, 1247-1251 (2011)

72. Hussell, T. \& Bell, T. J. Alveolar macrophages: plasticity in a tissue-specific context. Nat. Rev. Immunol. 14, 81-93 (2014).

73. Kopf, M., Schneider, C. \& Nobs, S. P. The development and function of lung-resident macrophages and dendritic cells. Nat. Immunol. 16, 36-44 (2015).

74. Torrelles, J. B. \& Schlesinger, L. S. Integrating lung physiology, immunology, and tuberculosis. Trends Microbiol. 25, 688-697 (2017).

75. Liu, C. H., Liu, H. \& Ge, B. Innate immunity in tuberculosis: host defense versus pathogen evasion Cell. Mol. Immunol. 14, 963-975 (2017).

76. Warren, E., Teskey, G \& Venketaraman, V. Effector mechanisms of neutrophils within the innate immune system in response to Mycobacterium tuberculosis infection. J. Clin. Med. 6, 15 (2017)

77. Mortaz, E. et al. Interaction of pattern recognition receptors with mycobacterium tuberculosis. J. Clin. Immunol. 35, 1-10 (2015).

78. Stamm, C. E., Collins, A. C. \& Shiloh, M. U. Sensing of Mycobacterium tuberculosis and consequences to both host and bacillus. Immunol. Rev. 264, 204-219 (2015).

79. Groschel, M. I., Sayes, F., Simeone, R., Majlessi, L. \& Brosch, R. ESX secretion systems: mycobacterial evolution to counter host immunity. Nat. Rev. Microbiol. 14, 677-691 (2016).

80. Fabri, M. et al. Vitamin D is required for IFN-gammamediated antimicrobial activity of human macrophages. Sci. Transl. Med. 3, 104ra102 (2011).

81. Collins, A. C. et al. Cyclic GMP-AMP synthase is an innate immune DNA sensor for Mycobacterium tuberculosis. Cell Host Microbe 17, 820-828 (2015).

82. Watson, R. O. et al. The cytosolic sensor cGAS detects Mycobacterium tuberculosis DNA to induce type I interferons and activate autophagy. Cell Host Microbe 17, 811-819 (2015).
83. Behar, S. M., Divangahi, M. \& Remold, H. G. Evasion of innate immunity by Mycobacterium tuberculosis: is death an exit strategy? Nat. Rev. Microbiol. 8, 668-674 (2010)

84. Verrall, A. J., Netea, M. G., Alisjahbana, B., Hill, P. C. $\&$ van Crevel, R. Early clearance of Mycobacterium tuberculosis: a new frontier in prevention. Immunology 141, 506-513 (2014).

85. Arbour, N. C. et al. TLR4 mutations are associated with endotoxin hyporesponsiveness in humans. Nat. Genet 25, 187-191 (2000).

86. Hawn, T. R. et al. A common dominant TLR5 stop codon polymorphism abolishes flagellin signaling and is associated with susceptibility to legionnaires disease. J. Exp. Med. 198, 1563-1572 (2003).

87. Hawn, T. R. et al. A common human TLR1 polymorphism regulates the innate immune response to lipopeptides. Eur. J. Immunol. 37, 2280-2289 (2007).

88. Hoffman, H. M., Mueller, J. L., Broide, D. H., Wanderer, A. A. \& Kolodner, R. D. Mutation of a new gene encoding a putative pyrin-like protein causes familial cold autoinflammatory syndrome and MuckleWells syndrome. Nat. Genet. 29, 301-305 (2001).

89. Ma, X. et al. Full-exon resequencing reveals toll-like receptor variants contribute to human susceptibility to tuberculosis disease. PLOS ONE 2, e1318 (2007)

90. Meyer, C. G. et al. TLR1 variant H305L associated with protection from pulmonary tuberculosis. PLOS ONE 11, e0156046 (2016).

91. Johnson, C. M. et al. Cutting edge: a common polymorphism impairs cell surface trafficking and functional responses of TLR1 but protects against leprosy. J. Immunol. 178, 7520-7524 (2007).

92. Velez, D. R. et al. Variants in toll-like receptors 2 and 9 influence susceptibility to pulmonary tuberculosis in Caucasians, African-Americans, and West Africans. Hum. Genet. 127, 65-73 (2010).

93. Davila, S. et al. Genetic association and expression studies indicate a role of toll-like receptor 8 in pulmonary tuberculosis. PLoS Genet. 4, e 1000218 (2008).

94. Hawn, T. R. et al. A polymorphism in Toll-interleukin 1 receptor domain containing adaptor protein is associated with susceptibility to meningeal tuberculosis. J. Infect. Dis. 194, 1127-1134 (2006).

95. Khor C. C et al. A Mal functional variant is associated with protection against invasive pneumococcal disease, bacteremia, malaria and tuberculosis. Nat. Genet. 39, 523-528 (2007).

96. Thuong, N. T. et al. A polymorphism in human TLR2 is associated with increased susceptibility to tuberculous meningitis. Genes Immun. 8, 422-428 (2007).

97. Shah, J. A. et al. Human TOLLIP regulates TLR2 and TLR4 signaling and its polymorphisms are associated with susceptibility to tuberculosis. J. Immunol. 189 1737-1746 (2012)

98. Shah, J. A. et al. Genetic variation in toll-interacting protein is associated with leprosy susceptibility and cutaneous expression of interleukin 1 receptor antagonist. J. Infect. Dis. 213, 1189-1197 (2016).

99. Barreiro, L. B. et al. Promoter variation in the DC-SIGN-encoding gene CD209 is associated with tuberculosis. PLoS Med. 3, e20 (2006).

100. Intemann, C. D. et al. Autophagy gene variant IRGM 261T contributes to protection from tuberculosis caused by Mycobacterium tuberculosis but not by $\mathrm{M}$. africanum strains. PLoS Pathog. 5, e1000577 (2009).

101. Lu, Y. et al. Association of autophagy-related IRGM polymorphisms with latent versus active tuberculosis infection in a Chinese population. Tuberculosis 97 , 47-51 (2016)

102. Tobin, D. M. et al. Host genotype-specific therapies can optimize the inflammatory response to mycobacterial infections. Cell 148, 434-446 (2012).

103. Picard, C. et al. Clinical features and outcome of patients with IRAK-4 and MyD88 deficiency. Medicine 89, 403-425 (2010)

104. Gutierrez, M. G. et al. Autophagy is a defense mechanism inhibiting BCG and Mycobacterium tuberculosis survival in infected macrophages. Cell 119, 753-766 (2004).

105. Singh, S. B., Davis, A. S., Taylor, G. A. \& Deretic, V. Human IRGM induces autophagy to eliminate intracellular mycobacteria. Science 313, 1438-1441 (2006).

106. Kumar, D. et al. Genome-wide analysis of the host intracellular network that regulates survival of Mycobacterium tuberculosis. Cell 140, 731-743 (2010). 
107. Watson, R. O., Manzanillo, P. S. \& Cox, J. S. Extracellular $M$. tuberculosis DNA targets bacteria for autophagy by activating the host DNA-sensing pathway. Cell 150, 803-815 (2012).

108. Majlessi, L. \& Brosch, R. Mycobacterium tuberculosis meets the cytosol: the role of cGAS in anti-mycobacterial immunity. Cell Host Microbe 17 733-735 (2015).

109. Romagnoli, A. et al. ESX-1 dependent impairment of autophagic flux by Mycobacterium tuberculosis in human dendritic cells. Autophagy 8, 1357-1370 (2012).

110. Castillo, E. F. et al. Autophagy protects against active tuberculosis by suppressing bacterial burden and inflammation. Proc. Natl Acad. Sci. USA 109 E3168-E3176 (2012)

111. Kimmey, J. M. et al. Unique role for ATG5 in neutrophil-mediated immunopathology during M. tuberculosis infection. Nature 528, 565-569 (2015).

112. Seshadri, C. et al. Transcriptional networks are associated with resistance to Mycobacterium tuberculosis infection. PLOS ONE 12, e0175844 (2017).

In this study, the transcriptional responses of monocytes from resisters and individuals with LTBI following ex vivo $M$. tuberculosis infection are shown to be distinct, and network analysis identifies HDACs as potential mediators of this difference.

113. Subramanian, A. et al. Gene set enrichment analysis: a knowledge-based approach for interpreting genome-wide expression profiles. Proc. Natl Acad. Sci. USA 102, 15545-15550 (2005).

114. Joseph, J. et al. Expression profiling of sodium butyrate $(\mathrm{NaB})$-treated cells: identification of regulation of genes related to cytokine signaling and cancer metastasis by NaB. Oncogene 23, 6304-6315 (2004).

115. Chandran, A. et al. Mycobacterium tuberculosis infection induces HDAC 1-mediated suppression of IL-12B gene expression in macrophages. Front. Cell. Infect. Microbiol. 5, 90 (2015).

116. Wang, Y., Curry, H. M., Zwilling, B. S. \& Lafuse, W. P. Mycobacteria inhibition of IFN-gamma induced HLA-DR gene expression by up-regulating histone deacetylation at the promoter region in human THP-1 monocytic cells. J. Immunol. 174, 5687-5694 (2005).

117. Coussens, A. K., Wilkinson, R. J. \& Martineau, A. R. Phenylbutyrate is bacteriostatic against Mycobacterium tuberculosis and regulates the macrophage response to infection, synergistically with 25-hydroxy-vitamin D3. PLoS Pathog. 11, e 1005007 (2015).

118. Mily, A. et al. Significant effects of oral phenylbutyrate and vitamin D3 adjunctive therapy in pulmonary tuberculosis: a randomized controlled trial. PLOS ONE 10, e0138340 (2015)

119. Behar, S. M., Dascher, C. C., Grusby, M. J., Wang, C. R. \& Brenner, M. B. Susceptibility of mice deficient in CD1D or TAP1 to infection with Mycobacterium tuberculosis. J. Exp. Med. 189, 1973-1980 (1999).

120. Lin, P. L. et al. CD4 T cell depletion exacerbates acute Mycobacterium tuberculosis while reactivation of latent infection is dependent on severity of tissue depletion in cynomolgus macaques. AIDS Res. Hum. Retroviruses 28, 1693-1702 (2012).

121. Mogues, T., Goodrich, M. E., Ryan, L., LaCourse, R. \& North, R. J. The relative importance of T cell subsets in immunity and immunopathology of airborne Mycobacterium tuberculosis infection in mice. J. Exp. Med. 193, 271-280 (2001)

122. Flynn, J. L. et al. An essential role for interferon gamma in resistance to Mycobacterium tuberculosis infection. J. Exp. Med. 178, 2249-2254 (1993).

123. Green, A. M., Difazio, R. \& Flynn, J. L. IFN-gamma from CD4 T cells is essential for host survival and enhances CD8 T cell function during Mycobacterium tuberculosis infection. J. Immunol. 190, 270-277 (2013)

124. Kagina, B. M. N. et al. Specific T cell frequency and cytokine expression profile do not correlate with protection against tuberculosis after bacillus CalmetteGuérin vaccination of newborns. Am. J. Respir. Crit. Care Med. 182, 1073-1079 (2010)

125. Tameris, M. D. et al. Safety and efficacy of MVA85A, a new tuberculosis vaccine, in infants previously vaccinated with BCG: a randomised, placebocontrolled phase $2 \mathrm{~b}$ trial. Lancet $381,1021-1028$ (2013).
126. Boussiotis, V. A. et al. IL-10-producing T cells suppress immune responses in anergic tuberculosis patients. J. Clin. Invest. 105, 1317-1325 (2000)

127. Delgado, J. C. et al. Antigen-specific and persistent tuberculin anergy in a cohort of pulmonary tuberculosis patients from rural Cambodia. Proc. Natl Acad. Sci. 99, 7576-7581 (2002).

This investigation of a subset of patients with pulmonary TB indicates that persistent in vivo anergy in the PPD skin reactivity test following treatment completion is not a global anergy but instead is PPD antigen-specific and is correlated with elevated IL-10 production and reduced secretion of IL-2 and IFN $\gamma$ by T cells following ex vivo stimulation with $P P D$ antigens.

128. Redford, P. S., Murray, P. J. \& O'Garra, A. The role of IL-10 in immune regulation during $M$. tuberculosis infection. Mucosal Immunol. 4, 261-270 (2011).

129. Thye, T. et al. IL10 haplotype associated with tuberculin skin test response but not with pulmonary TB. PLOS ONE 4, e5420 (2009).

130. Okamoto Yoshida, Y. et al. Essential role of IL-17A in the formation of a mycobacterial infection-induced granuloma in the lung. J. Immunol. 184, 4414-4422 (2010).

131. Wozniak, T. M., Saunders, B. M., Ryan, A. A. \& Britton, W. J. Mycobacterium bovis BCG-specific Th1 7 cells confer partial protection against Mycobacterium tuberculosis infection in the absence of gamma interferon. Infect. Immun. 78, 4187-4194 (2010).

132. Gallegos, A. M. et al. A gamma interferon independent mechanism of CD4 T cell mediated control of M. tuberculosis infection in vivo. PLoS Pathog. 7 e1002052 (2011).

133. Han, M. \& Hannick, L. I., DiBrino, M. \& Robinson, M. A Polymorphism of human CD1 genes. Tissue Antigens 54, 122-127 (1999)

134. Oteo, M. et al. Single strand conformational polymorphism analysis of human $\mathrm{CD} 1$ genes in different ethnic groups. Tissue Antigens 53, 545-550 (1999).

135. Seshadri, C. et al. T cell responses against mycobacterial lipids and proteins are poorly correlated in South African adolescents. J. Immunol. 195, 4595-4603 (2015).

This study shows that the response of $\mathrm{CD4}^{+} \mathrm{T}$ cells to mycobacterial lipid (CD1-restricted) antigens ex vivo correlates poorly with their response to peptide antigens. However, as the abundance of lipid-specific $T$ cells does not differ between infected and uninfected individuals in this study, it is plausible that individuals negative for the IGRA are $M$. tuberculosis-exposed and that their T cells produce a similar repertoire of cytokines as those from IGRA-positive individuals, although they do not secrete IFN $\gamma$

136. Van Rhijn, I. Ly, D. \& Moody, D. B. CD1a, CD1b, and CD1c in immunity against mycobacteria. Adv. Exp. Med. Biol. 783, 181-197 (2013)

137. Kjer-Nielsen, L. et al. MR1 presents microbial vitamin B metabolites to MAIT cells. Nature 491, 717-723 (2012).

138. Martin, E. et al. Stepwise development of mait cells in mouse and human. PLoS Biol. 7, 0525-0536 (2009).

139. Porcelli, S., Yockey, C. E., Brenner, M. B. \& Balk, S. P. Analysis of T cell antigen receptor (TCR) expression by human peripheral blood CD4-8- alpha/beta T cells demonstrates preferential use of several $\mathrm{V}$ beta genes and an invariant TCR alpha chain. J. Exp. Med. 178. $1-16$ (1993).

140. Treiner, E. et al. Selection of evolutionarily conserved mucosal-associated invariant T cells by MR1. Nature 422, 164-169 (2003).

141. Chua, W. J. et al. Polyclonal mucosa-associated invariant $\mathrm{T}$ cells have unique innate functions in bacterial infection. Infect. Immun. 80, 3256-3267 (2012).

142. Seshadri, C. et al. A polymorphism in human MR1 is associated with mRNA expression and susceptibility to tuberculosis. Genes Immun. 18, 8-14 (2017).

143. Seshadri, C. et al. A polymorphism in human CD1A is associated with susceptibility to tuberculosis. Genes Immun. 15, 195-198 (2014).

144. Sandstrom, A. et al. The intracellular B30.2 domain of butyrophilin 3A1 binds phosphoantigens to mediate activation of human V $\gamma 9 \mathrm{~V} \delta 2 \mathrm{~T}$ Cells. Immunity 40 , 490-500 (2014).

145. Vavassori, S. et al. Butyrophilin 3A1 binds phosphorylated antigens and stimulates human $\gamma \delta$ T cells. Nat. Immunol. 14, 908-916 (2013).
146. Spencer, C. T., Abate, G., Blazevic, A. \& Hoft, D. F Only a subset of phosphoantigen-responsive $92 \mathrm{~T}$ cells mediate protective tuberculosis immunity. J. Immunol. 181, 4471-4484 (2008)

147. Plotkin, S. A. Vaccines: correlates of vaccine-induced immunity. Clin. Infect. Dis. 47, 401-409 (2008).

148. Plotkin, S. A. Correlates of protection induced by vaccination. Clin. Vaccine Immunol. 17, 1055-1065 (2010).

149. Achkar, J. M., Chan, J. \& Casadevall, A. B cells and antibodies in the defense against Mycobacterium tuberculosis infection. Immunol. Rev. 264, 167-181 (2015).

150. Kozakiewicz, L., Phuah, J., Flynn, J. \& Chan, J. The role of B cells and humoral immunity in Mycobacterium tuberculosis infection. Adv. Exp. Med. Biol. 783, 225-250 (2013).

151. Balu, S. et al. A novel human IgA monoclonal antibody protects against tuberculosis. J. Immunol. 186, 3113-3119 (2011)

152. Hamasur, B. et al. A mycobacterial lipoarabinomannan specific monoclonal antibody and its $F\left(a b^{\prime}\right)$ fragment prolong survival of mice infected with Mycobacterium tuberculosis. Clin. Exp. Immunol. 138, 30-38 (2004)

153. Suter, E. Multiplication of tubercle bacilli within mononuclear phagocytes in tissue cultures derived from normal animals and animals vaccinated with BCG. J. Exp. Med. 97, 235-245 (1953).

154. Teitelbaum, R. et al. A mAb recognizing a surface antigen of Mycobacterium tuberculosis enhances host survival. Proc. Natl Acad. Sci. USA 95, 15688-15693 (1998).

155. Glatman-Freedman, A. \& Casadevall, A. Serum therapy for tuberculosis revisited: reappraisal of the role of antibody-mediated immunity against Mycobacterium tuberculosis. Clin. Microbiol. Rev. 11, 514-532 (1998)

156. Fletcher, H. A et al. T cell activation is an immune correlate of risk in BCG vaccinated infants. Nat Commun. 7, 11290 (2016).

157. Phuah, J. et al. Effects of B cell depletion on early Mycobacterium tuberculosis infection in cynomolgus macaques. Infect. Immun. 84, 1301-1311 (2016).

158. Abreu, M. T. et al. Alterations in the peripheral blood B cell subpopulations of multidrug-resistant tuberculosis patients. Clin. Exp. Med. 14, 423-429 (2014).

159. Joosten, S. A. et al. Patients with tuberculosis have a dysfunctional circulating B-cell compartment, which normalizes following successful treatment. PLOS Pathog. 12, e 1005687 (2016)

160. Phuah, J. Y., Mattila, J. T., Lin, P. L. \& Flynn, J. L. Activated $B$ cells in the granulomas of nonhuman primates infected with Mycobacterium tuberculosis. Am. J. Pathol. 181, 508-514 (2012)

161. Tsai, M. C. et al. Characterization of the tuberculous granuloma in murine and human lungs: cellular composition and relative tissue oxygen tension. Cell. Microbiol. 8, 218-232 (2006).

162. Casadevall, A. \& Pirofski, L. A. A reappraisal of humoral immunity based on mechanisms of antibodymediated protection against intracellular pathogens. Adv. Immunol. 91, 1-44 (2006).

163. Nimmerjahn, F. \& Ravetch, J. V. Fcgamma receptors as regulators of immune responses. Nat. Rev. Immunol. 8, 34-47 (2008)

164. Lu, L. L. et al. A functional role for antibodies in tuberculosis. Cell 167, 433-443 e414 (2016). In this study, antibody profiling indicates that the pattern of glycosylation in the Fc domain of antibodies from individuals with LTBI is distinct from that of antibodies from patients with active TB and that addition of latent antibodies to macrophages previously infected with $M$. tuberculosis results in improved phagolysosomal maturation and killing of intracellular bacteria by these macrophages.

165. Riedel, S. Edward Jenner and the history of smallpox and vaccination. Proc 18, 21-25 (2005).

166. Liu, R. et al. Homozygous defect in HIV-1 corecepto accounts for resistance of some multiply-exposed individuals to HIV-1 infection. Cell 86, 367-377 (1996).

167. Samson, M. et al. Resistance to HIV-1 infection in caucasian individuals bearing mutant alleles of the CCR-5 chemokine receptor gene. Nature 382 , 722-725 (1996)

168. Gulick, R. M. et al. Maraviroc for previously treated patients with R5 HIV-1 infection. N. Engl. J. Med. 359 1429-1441 (2008).

169. Jones-Lopez, E. C. et al. Cough Aerosols of Mycobacterium tuberculosis in the prediction of 
incident tuberculosis disease in household contacts. Clin. Infect. Dis. 63, 10-20 (2016).

170. Patterson, B. et al. Detection of Mycobacterium tuberculosis bacilli in bio-aerosols from untreated TB patients. Gates Open Res. 1, 11 (2017).

171. Zwerling, A. et al. Trajectories of tuberculosis-specific interferon-gamma release assay responses among medical and nursing students in rural India J. Epidemiol. Glob. Health 3, 105-117 (2013).

172. Gagneux, S. et al. Variable host-pathogen compatibility in Mycobacterium tuberculosis. Proc. Natl Acad. Sci. USA 103, 2869-2873 (2006).

173. Hardy, M. A. \& Schmidek, H. H. Epidemiology of tuberculosis aboard a ship. JAMA 203, 175-179 (1968).

174. Badger, T. L. \& Spink, W. W. First-infection type of tuberculosis in adults - a five-year study of student nurses at the Boston City Hospital. New Engl. J. Med. 217, 424-431 (1937).

175. Myers, J. A., Boynton, R. E. \& Diehl, R. E. Prevention of tuberculosis among students of nursing.

Am. J. Nurs. 47, 661-666 (1947).
176. Dickie, H. A. Tuberculosis in student nurses and medical students at the University of Wisconsin. Ann. Intern. Med. 33, 941-959 (1950).

177. Stein, C. M. et al. Resistance and susceptibility to Mycobacterium tuberculosis infection and disease in tuberculosis households in Kampala, Uganda

Am. J. Epidemiol. https://doi.org/10.1093/aje/kwx380 (2018).

Acknowledgements

This work was supported by grants from the US National Institutes of Health grants R01Al124348 (to W.H.B., T.R.H., C.S., C.M.S. and H.M.-K.), U01Al115642 (to W.H.B., T.R.H C.S., C.M.S. and H.M.-K.), R01Al 124349 (to E.S.) and T32AI007044 (to J.D.S.) and contract number NO1 AI70022 (to W.H.B., C.M.S., T.R.H. and H.M.-K.); the Bill and Melinda Gates Foundation grant OPP 1151836 (to T.R.H., W.H.B., C.S. C.M.S., H.M.-K., G.C. and R.S.W.) and grant OPP1151840 (to G.A. and S.F.); the Canadian Institutes of Health Research grant FDN 143332 (to E.S.); and the South African Medical Research Council grant ACT4TB/HIV (to G.C. and R.S.W.). G.C. is also affiliated with the School of Public Health, University of
Witwatersrand, Johannesburg, South Africa, and the Advancing Care and Treatment for TB/HIV, South African Medical Research Council, Johannesburg, South Africa. E.S. is also affiliated with the McGill International TB Centre, McGill University, Montreal, Quebec, Canada.

\section{Author contributions}

J.D.S., C.S. and T.R.H. contributed to the drafting and editing of all sections. Focused contributions were made to the Epidemiology and Genetics sections (C.M.S., E.S. and G.C.), the B cell-mediated resistance section (G.A.) and the Macrophage-mediated resistance section (M.C.). Initial figure drafts were provided by J.D.S., M.C. and G.A. Detailed review and editing were additionally provided by S.F., R.S.W., W.H.B. and H.M. K.

\section{Competing interests}

The authors declare no competing interests.

Publisher's note

Springer Nature remains neutral with regard to jurisdictional claims in published maps and institutional affiliations. 